\title{
The unique stem cell system of the immortal larva of the human parasite Echinococcus multilocularis
}

\author{
Uriel Koziol ${ }^{1,3}$, Theresa Rauschendorfer ${ }^{1}$, Luis Zanon Rodríguez ${ }^{1}$ Georg Krohne ${ }^{2}$ and Klaus Brehm*
}

\begin{abstract}
Background: It is believed that in tapeworms a separate population of undifferentiated cells, the germinative cells, is the only source of cell proliferation throughout the life cycle (similar to the neoblasts of free living flatworms). In Echinococcus multilocularis, the metacestode larval stage has a unique development, growing continuously like a mass of vesicles that infiltrate the tissues of the intermediate host, generating multiple protoscoleces by asexual budding. This unique proliferation potential indicates the existence of stem cells that are totipotent and have the ability for extensive self-renewal.

Results: We show that only the germinative cells proliferate in the larval vesicles and in primary cell cultures that undergo complete vesicle regeneration, by using a combination of morphological criteria and by developing molecular markers of differentiated cell types. The germinative cells are homogeneous in morphology but heterogeneous at the molecular level, since only sub-populations express homologs of the post-transcriptional regulators nanos and argonaute. Important differences are observed between the expression patterns of selected neoblast marker genes of other flatworms and the E. multilocularis germinative cells, including widespread expression in E. multilocularis of some genes that are neoblast-specific in planarians. Hydroxyurea treatment results in the depletion of germinative cells in larval vesicles, and after recovery following hydroxyurea treatment, surviving proliferating cells grow as patches that suggest extensive self-renewal potential for individual germinative cells.

Conclusions: In E. multilocularis metacestodes, the germinative cells are the only proliferating cells, presumably driving the continuous growth of the larval vesicles. However, the existence of sub-populations of the germinative cells is strongly supported by our data. Although the germinative cells are very similar to the neoblasts of other flatworms in function and in undifferentiated morphology, their unique gene expression pattern and the evolutionary loss of conserved stem cells regulators suggest that important differences in their physiology exist, which could be related to the unique biology of E. multilocularis larvae.
\end{abstract}

Keywords: Cestoda, Echinococcus, Neoblast, Germinative cell, Stem cell, Nanos, Argonaute, Mucin, Alkaline phosphatase

\section{Background}

The Platyhelminthes (flatworms) comprise a highly diverse phylum in terms of morphology, embryology, life-cycle complexity and capacity for regeneration and asexual reproduction [1-4]. However, they are united by having a unique population of undifferentiated stem cells, commonly known as 'neoblasts' $[5,6]$. It is thought that neoblasts represent the only proliferative cell population, and

\footnotetext{
* Correspondence: kbrehm@hygiene.uni-wuerzburg.de

${ }^{1}$ Institute of Hygiene and Microbiology, University of Würzburg,

Josef-Schneider-Strasse 2, D-97080 Würzburg, Germany

Full list of author information is available at the end of the article
}

are therefore the source of new cells for normal tissue turnover, growth and regeneration.

The characterization of neoblasts has been most extensive for free living flatworms, especially for planarians. Planarian neoblasts have been shown to be truly pluripotent [7], and are essential for planarian regeneration [8]. Classical ultrastructural studies in planarians described the neoblasts as small, round cells with a large nucleus containing little heterochromatin and a large nucleolus, with scant cytoplasm containing mitochondria, abundant free ribosomes and few other organelles $[9,10]$. Furthermore, they possess cytoplasmic electrondense ribonucleoprotein (RNP) granules called chromatoid 
bodies, which are molecularly and morphologically similar to the well known germ granules present in the germ cells of many animals. Germ granules are thought to function as centers for post-transcriptional regulation of mRNA, similar to other RNP bodies in somatic cells $[11,12]$. Many studies have shown that genes involved in posttranscriptional regulation and chromatin modification are highly upregulated in neoblasts [13-18]. These include genes that are typically considered markers of germ cells in other model animals, such as the DEAD box RNA helicase vasa and the Argonaute family gene piwi [11]. This expression of germ line markers in somatic multipotent stem cells has also been found in other animal lineages, and has been interpreted as part of a multipotency program conserved between the germ line and multipotent somatic stem cells [19]. The development of molecular markers has further shown that the neoblasts are actually heterogeneous at the molecular level $[9,10]$.

The main groups of parasitic flatworms, including cestodes, trematodes and monogeneans, form the monophyletic clade Neodermata [4,20]. In cestodes, classical studies have evidenced a population of undifferentiated stem cell similar to the neoblasts, which are denominated the germinative cells [21-28]. However, unlike for planarian neoblasts, chromatoid bodies have never been described for the germinative cells. Germinative cells are thought to drive the development throughout the cestode life cycle. In the 'typical' cestode life cycle, the oncosphere (first larval stage) is a highly reduced organism that has a small population of set-aside germinative cells. Once the oncosphere infects the intermediate host, it develops into the metacestode (second larval stage), and it is thought that only the germinative cells contribute to this metamorphosis [29]. Usually, the metacestode is similar to a 'juvenile' tapeworm, containing the scolex (head) with the attachment organs, but lacking the reproductive systems. Finally, the intermediate host containing the metacestode is ingested by the definitive host, and the metacestode develops into an adult in the intestine. New segments, each containing a complete set of male and female reproductive systems, are generated continuously from the proliferative region of the neck, behind the scolex, and produce oncospheres by sexual reproduction. In the neck region of segmenting cestodes, the proliferating germinative cells are localized close to the inner muscle layer, and have been shown to be the only proliferating cell type [22-24,27,30].

The metacestode stage of Echinococcus multilocularis is atypical in its development and morphology [31-33]. After the oncosphere is ingested by the intermediate host (diverse rodents, but also accidentally by humans) it develops in the liver as a labyrinth of vesicles, which grow cancer-like and infiltrate the tissue of the host, forming new vesicles and even metastases. The metacestode growth causes the disease alveolar echinococcosis, one of the most dangerous zoonoses of the Northern Hemisphere [33]. The metacestode vesicles comprise a thin layer of tissue (the germinal layer) covered by a syncitialtegument that secretes an acellular, carbohydrate-rich external layer (the laminated layer) (Figure 1). The remaining volume of the vesicles is filled with fluid (hydatid fluid). Within the germinal layer, thickenings (buds) occur that invaginate into the vesicle, resulting in the formation of brood capsules (Figure 1A). Within the brood capsules, a new budding process occurs, that results in the formation of protoscoleces, the infective form for the definitive host (Figure 1B-C). The protoscolex already resembles the anterior region of the adult form, with a scolex that lays invaginated within a small posterior body (Figure 1D). After ingestion of the protoscolex by the definitive host (canids), it evaginates its scolex, attaches to the intestine and develops into the adult tapeworm [33].

The metacestode tissue can be maintained and will grow indefinitely in intermediate hosts by serial passage, and is in this sense 'immortal' [34,35]. Recently, we have developed methods for the axenic in vitro maintenance of metacestode vesicles, and for primary cell cultures that result in complete regeneration of metacestode vesicles [36]. These methods allow for in vitro analysis of development in Echinococcus metacestodes, and show that at least at a population level, the primary cell preparations are multipotent. Classical ultrastructural studies in E. multilocularis and the related Echinococcus granulosus demonstrated the existence of germinative cells in the germinal layer, which proliferate and accumulate during brood capsule and protoscolex development [28]. This accumulation of proliferating cells in the developing protoscolex was confirmed by labeling with radioactive thymidine [37]. Nothing is known to date about gene expression in cestode germinative cells, but the genome sequencing project of E. multilocularis demonstrated the lack of vasa and piwi orthologs, suggesting fundamental differences between germinative cells and planarian neoblasts [38]. Differentiated cell types have also been described in the germinal layer, including tegumental cells (the cell bodies of the tegumental syncitium, which are connected to the overlying syncitial tegument by cytoplasmatic bridges), muscle cells, glycogen/lipid storing cells, and recently, nerve cells $[28,39,40]$.

In this work, we characterize the germinative cells in the metacestodes and in primary cell cultures as the only proliferating cells, driving metacestode growth and regeneration. By developing methods for analyzing gene expression with cellular resolution in E. multilocularis, we show that differentiated cell types do not proliferate, and that the germinative cells are heterogeneous at the molecular level, showing in addition several differences with the neoblasts from other flatworms. Finally, by 


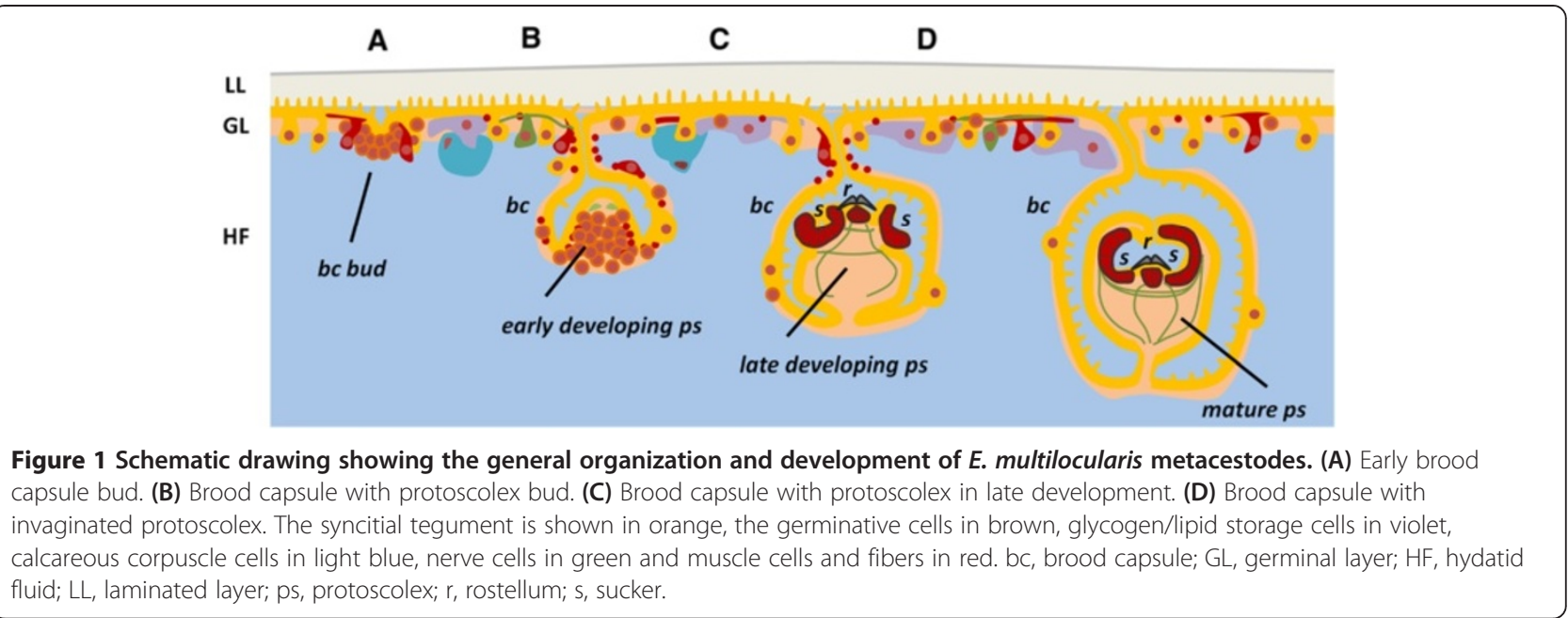

analyzing the response of the metacestodes after partial germinative cell depletion, we provide evidence that indicates extensive self-renewal capabilities for individual germinative cells.

\section{Methods}

Parasite material, culture and primary cell preparation Parasite isolates were maintained by serial intraperitoneal passage in Meriones unguiculatus as previously described [34]. Unless otherwise stated, all experiments were performed on in vitro cultured metacestodes. Standard in vitro culture of metacestodes was done in co-culture with rat Reuber hepatoma feeder cells, and primary cell preparations were performed and cultured in cDMEM-A pre-conditioned medium essentially as previously described [34], with the following modifications: 1) cells were detached from the metacestode tissue with a single treatment of 20 minutes with trypsin/ethylenediaminetetraacetic acid (EDTA) and 2) primary cells were cultured in CDMEM-A instead of hydatid fluid.

For primary cell cultures, isolate H95 [41], which has been passaged for 18 years and has developed a strong defect in protoscolex formation was used. For other experiments, more recent isolates were used, obtained from accidental infections of Old World Monkeys in a breeding exclosure [42]. Dugesia tahitiensis ([43], obtained from Bernhard Egger) was the planarian species used for immunohistofluorescence.

\section{Ethical approval}

All experiments were carried out in accordance with European and German regulations on the protection of animals (Tierschutzgesetz). Ethical approval of the study was obtained from the local ethics committee of the government of Lower Franconia (55.2-2531.01-31/10).

\section{EdU labeling and detection}

For short term labeling, $50 \mu \mathrm{M}$ of 5-ethynyl-2'-deoxyuridine (EdU, Life Technologies, Darmstadt, Germany) was added to the media and the material was incubated for five hours. For continuous labeling, $1 \mu \mathrm{M}$ EdU was used for up to 14 days. The length of incubation and the EdU concentrations were determined after varying the parameters in preliminary experiments (see the main text). Before fixation, metacestode vesicles were gently opened using a syringe tip in order to allow the entry of the fixative and other reagents during detection procedures. Samples were fixed in 4\% paraformaldehyde prepared in PBS (PFA-PBS) for one hour at room temperature, and processed for detection of EdU in paraplast sections. Detection was performed with the Click-iT $\mathrm{T}^{\bullet}$ EdU Alexa Fluor 555 Imaging Kit (Life Technologies, Darmstadt, Germany) as described by the manufacturer for sections. Whole-mount detection was performed by a modified protocol in which all steps were doubled in length and the washes were increased in number. For double labeling, EdU detection was always performed after the immunohistofluorescence or in situ hybridization protocols.

\section{Tissue maceration and staining of cell suspensions}

Cell suspensions were prepared by a modification of the method of David [44]. Metacestode vesicles were opened and washed in PBS and placed in maceration solution (13:1:1 distilled water: glacial acetic acid: glycerol, $100 \mu \mathrm{l}$ of solution per vesicle). Primary cell aggregates (from one well of a six-well plate, after two days of culture) were washed in PBS, allowed to settle and placed in 500 $\mu \mathrm{l}$ of maceration solution. Both kinds of samples were pipetted up and down with a p1000 pipette, and placed overnight at $4^{\circ} \mathrm{C}$. The next day they were once again disaggregated by pipetting, diluted to 1:10 with maceration solution, and $10 \mu \mathrm{l}$ were spotted on SuperFrost slides 
(Thermo Scientific). The slides were dried overnight at room temperature and stained by either of these procedures:

A) PI plus DAPI: after washing the slides with PBS plus $0.05 \%$ Triton X-100, the slides were stained successively with DAPI (1 ug/ml in PBS) and PI (2.5 ug/ml in PBS), washed twice with PBS and mounted with Fluoprep (bioMérieux).

B) WCS plus DAPI: the Cellomics ${ }^{\mathrm{TM}}$ WCS Green (Thermo Scientific) was used as instructed by the manufacturer, followed by DAPI staining, washing and Fluoprep mounting. When done in combination, EdU detection was performed first, followed by WCS plus DAPI staining.

C) Nile red plus DAPI: after washing with PBS, the slides were stained with Nile Red [45] (SigmaAldrich, Hamburg, Germany; $100 \mathrm{ng} / \mathrm{ml}$ in PBS from a $4.2 \mathrm{mg} / \mathrm{ml}$ stock in acetone) followed by DAPI staining, washing, and Fluoprep mounting (Biomerieux, Nürtingen, Germany). Imaging was performed with the rhodamine channel of the Zeiss Axio Imager.Z1 microscope (Zeiss, Hamburg, Germany).

\section{Hydroxyurea treatment and X-ray irradiation}

Metacestode vesicles were cultured in axenic, pre-conditioned cDMEM-A medium [34] with a nitrogen gas phase (40 vesicles in $5 \mathrm{ml}$ of medium in $25 \mathrm{~cm}^{2}$ cell culture flasks, vertically positioned). $\mathrm{HU}$ was added to a final concentration of $40 \mathrm{mM}$ from a $2 \mathrm{M}$ stock (dissolved in medium), whereas only medium was added to controls. HU was added daily to the medium since it is not stable in solution at temperatures circa $37^{\circ} \mathrm{C}$ [46], and the medium was replaced every two days. After seven days of treatment, the vesicles were washed extensively and transferred to HU-free medium. Some vesicles were fixed immediately for immunohistofluorescence and whole-mount in situ hybridization. The remaining vesicles were kept in $\mathrm{HU}$-free medium, taking samples for EdU labeling after 1, 4, 9 and 22 days.

Determination of BrdU incorporation in primary cells after HU treatment was done with the Cell Proliferation Elisa, BrdU (Colorimetric) Kit (Roche). Briefly, primary cells were cultured in the presence of 0,10 or $40 \mathrm{mM}$ HU for 40 hours, after which half of the medium was replaced with fresh medium containing $\mathrm{HU}$ and BrdU (10 $\mu \mathrm{M}$, final concentration). The cells were cultured for four hours and processed for detection as indicated by the manufacturer. For studying the effect of $\mathrm{HU}$ on regeneration, primary cells were cultured with 0,10 or 40 $\mathrm{mM} \mathrm{HU}$, changing the medium and HU every 48 to 72 hours. After three weeks, the number of newly formed vesicles was counted.

For X-ray irradiation, a 150 Gy dose was applied to metacestodes with a Faxitron CP160 source (Faxitron,
Much, Germany). Vesicles were then set back into axenic culture, taking samples for EdU labeling after 2, 7, 20 and 48 days. Surviving metacestodes were defined as vesicles being able to maintain turgency and with an apparently intact germinal layer as seen under a dissecting microscope.

\section{PCR, RT-PCR and molecular cloning}

For RT-PCR, RNA was extracted with Tri-Reagent (5 PRIME) and $700 \mathrm{ng}$ of total RNA were used for cDNA synthesis using PrimeScript reverse transcriptase (Takara). For the analysis of genes lacking introns, RNA was previously treated with RQ1 DNase (Promega, 2 units/ $\mu \mathrm{g}$ for one hour) and mock controls with no reverse transcriptase were done in parallel to ensure that no amplification was obtained from contaminating genomic DNA. For genes with introns, primers were always designed in two separate exons. A list of primers and annealing temperatures, together with the E. multilocularis GeneDB codes (http:// www.genedb.org/Homepage/Emultilocularis), is included as supplementary material for all genes (Additional file 1).

For semi-quantitative RT-PCR, ten-fold serial dilutions of each cDNA were used for PCR with Taq polymerase (New England Biolabs), and the amplification was limited to 28 to 30 cycles. For normalization, RT-PCR with the constitutive gene em-elp [47] was performed.

For the cloning of gene fragments for whole-mount in situ hybridization, to confirm the complete coding domain sequences (CDS) of genes and for long-range PCR with genomic DNA, KOD Hot Start polymerase (Millipore) was used following the manufacturer's instructions. In the case of em-ago2- $A$, the $5^{\prime}$-region of the gene is interrupted by the end of the genomic scaffold. We obtained most of the $5^{\prime}$-region of the CDS by taking advantage of the high similarity between the em-ago 2 genes, using a combination of a specific em-ago2- $A$ primer with a primer for the 5 'end of em-ago2-B. PCR products for sequencing and probe synthesis were cloned into pDrive (Qiagen, Hilden, Germany) or pJet1.2 (Thermo Scientific, Schwerte, Germany).

\section{Alkaline phosphatase histochemistry}

Alkaline phosphatase histochemistry was done in cryosections and whole-mounts with nitro blue tetrazolium chloride and 5-bromo-4-chloro-3-indolyl phosphate (NBT/BCIP) as described by Cox and Singer [48].

\section{Immunohistochemistry and immunohistofluorescence}

Immunohistochemistry and immunohistofluorescence in paraplast sections and cryosections, and whole-mount immunohistofluorescence were performed as previously described [40,49]. For anti-PHB1 and anti-H3S10-P, a step of heat induced epitope retrieval was included after re-hydration, by boiling the slides for 20 minutes in a 
microwave in a solution of $10 \mathrm{mM}$ sodium citrate, $\mathrm{pH}$ 6.0 with $0.1 \%$ Triton X-100.

Primary antibodies used were Anti-PHB1 (rabbit polyclonal, Sigma-Aldrich HPA003280, 1:100 dilution), antiphospho-histone H3 (Ser10) (rabbit polyclonal, Cell Signaling Technology, Frankfurt/Main, Germany, code 9701, 1:100 dilution), anti-FMRFamide (Immunostar, Hudson, USA, code 20091), anti-HMW-tropomyosin $([49,50], \quad 1: 500$ dilution) and anti-acetylated tubulin (mouse monoclonal, clone 6-11B-1, Santa Cruz Biotechnology, Heidelberg, Germany, 1:100 dilution). In the case of anti-PHB1, we also performed a Western blot analysis with protein extracts of E. multilocularis metacestodes that confirmed that the antibody recognized a protein of the expected size. Secondary antibodies used were anti-mouse conjugated to FITC, anti-rabbit conjugated to FITC and anti-rabbit conjugated to peroxidase (Jackson ImmunoResearch, West Grove, PA, USA).

\section{Whole-mount in situ hybridization (WMISH)}

Digoxigenin-labeled probes were synthesized by in vitro transcription with T7 or SP6 polymerases (New England Biolabs), using the DIG RNA labeling mix (Roche) as described by the manufacturer, from a fragment of the relevant gene cloned into pDrive or pJet1.2 (previously linearized by digestion after the gene fragment with the appropriate restriction enzyme). A list of the probes used and their lengths is described for each gene in Additional file 1 . The probes were then purified with the RNeasy Mini Kit (Qiagen), checked by agarose gel electrophoresis and quantified by comparison of serial dilutions in a dot blot with the DIG-labeled Control RNA (Roche).

The WMISH protocol was adapted from the one used in the laboratory of Peter Olson (http://www.olsonlab. $\mathrm{com} /$ ). All solutions used up to the hybridization step were RNAse free by treatment with diethyl pyrocarbonate (DEPC). The metacestode vesicles (with or without developing protoscoleces) were opened with a syringe tip and fixed in PFA-PBS overnight at $4^{\circ} \mathrm{C}$. The next day, the samples were washed twice in $100 \%$ methanol, and kept at $20^{\circ} \mathrm{C}$ in methanol until further use. The vesicles were then transferred to $100 \%$ ethanol, rehydrated by successive steps in $75 \%$ and $50 \%$ ethanol in PBS, and washed extensively with PBS plus $0.1 \%$ Tween-20 (PBS-T). The tissue was then permeabilized with $15 \mu \mathrm{g} / \mathrm{ml}$ Proteinase K (Fermentas) in PBS-T for ten minutes, rinsed twice for five minutes in $0.1 \mathrm{M}$ triethanolamine (TEA), $\mathrm{pH} 8$, and treated twice with $0.25 \% \mathrm{v} / \mathrm{v}$ acetic anhydride in TEA buffer for five minutes. After washing twice for five minutes with PBS-T, the samples were re-fixed for 20 minutes in PFA-PBS at room temperature and washed extensively with PBS-T.

Samples were then transferred to pre-hybridization buffer (50\% formamide, $5 \mathrm{X}$ saline-sodium citrate buffer
(SSC) buffer [51], $1 \mathrm{mg} / \mathrm{ml}$ Torula yeast RNA, $100 \mathrm{ug} /$ $\mathrm{ml}$ heparin, $1 \mathrm{X}$ Denhardt's solution, $0.1 \%$ Tween-20, and $0.1 \%$ 3-[(3-cholamidopropyl)dimethylammonio]-1propanesulfonate (CHAPS); all components were obtained from Sigma-Aldrich). The buffer was changed twice before pre-hybridizing for 6 to 24 hours at $60^{\circ} \mathrm{C}$. Probes were then denatured by heating at $80^{\circ} \mathrm{C}$ for three minutes and placing directly on ice for three minutes, and added to the specimens at a concentration of 0.2 to $2 \mathrm{ng} / \mathrm{ul}$. Hybridization was performed at 53 to $54^{\circ} \mathrm{C}$ (for the shorter probes for em-muc-1 and em- $h 2 b$ of circa $200 \mathrm{bp}$ ) or at 57 to $58^{\circ} \mathrm{C}$ (for other probes) for 16 to 24 hours with constant shaking.

After hybridization, the samples were washed twice with the pre-hybridization buffer for ten minutes at $57^{\circ} \mathrm{C}$, three times in SSC $2 \mathrm{X}$ plus $0.1 \%$ Tween-20 for 20 minutes at $57^{\circ} \mathrm{C}$, and three times with $\mathrm{SSC} 0.2 \mathrm{X}$ plus $0.1 \%$ Tween- 20 at $57^{\circ} \mathrm{C}$. Samples were then transferred to room temperature, washed twice with maleic acid buffer (MAB-T: $100 \mathrm{mM}$ maleic acid, $150 \mathrm{mM} \mathrm{NaCl}$, $0.1 \%$ Tween-20) and blocked for two hours at room temperature with blocking buffer (MAB-T plus $1 \% \mathrm{w} / \mathrm{v}$ blocking reagent for nucleic acid hybridization and detection, (Roche), and 5\% v/v heat-inactivated sheep serum (Sigma-Aldrich)). Then they were incubated overnight with shaking at $4^{\circ} \mathrm{C}$ with anti-digoxigenin antibodies conjugated to either alkaline phosphatase or to peroxidase (Roche) in blocking buffer without sheep serum.

Finally, samples were extensively washed with MAB-T and development was performed with NBT/BCIP for alkaline phosphatase conjugated antibodies (conventional WMISH), or with fluorescein-tyramide for peroxidase antibodies, prepared and used as described by Hopman et al. [52] (fluorescent WMISH). Control sense probes were also used for all genes except em-tpm-1.hmw, and at least one control sense probe was included in all WMISH experiments, with no resulting signal (examples are included in Additional file 2).

\section{Fluorescence microscopy}

Samples were analyzed by confocal microscopy (Leica TCS SP5; Leica Microsystems, Wetzlar, Germany) and by epifluorescence microscopy (ZeissAxio Imager.Z1 (Zeiss, Hamburg, Germany) and Keyence BZ9000 (Keyence, Neu-Isenburg, Germany)). For the quantification of EdU + and AcTub + cells, at least four random microscopic fields were captured for each whole-mount metacestode vesicle, from which the positive cells were manually counted and averaged.

\section{Transmission Electron Microscopy (TEM)}

Protocols for TEM were performed as previously described [36]. 


\section{Results}

Cell proliferation in E. multilocularis larval development In order to detect proliferating cells, we incubated metacestode vesicles from in vitro culture with the thymidine analog 5-ethynyl-2'-deoxyuridine (EdU) [53], which is incorporated into DNA during its synthesis in the $\mathrm{S}$-phase of the cell cycle, and later performed the fluorescent detection reaction on metacestode whole-mounts and Sections. A relatively long time (two hours) and high concentration of EdU $(10 \mu \mathrm{M})$ was required for any labeling to be detected, probably because of slow equilibration between the EdU concentration in the medium and in the large amount of hydatid fluid within the vesicles. For typical labeling experiments, we used a fivehour incubation time and $50 \mu \mathrm{M}$ EdU. EdU positive $(\mathrm{EdU}+)$ cells can be detected throughout the germinal layer, and are in average $5.9 \%$ of all the cells ( $n=6$ independent labeling experiments, with $>200$ cells per experiment; range $=2.4 \%$ to $10.9 \%$ ) (Figure $2 \mathrm{~A}$ ). The vast majority of the labeled cells were in interphase, but a few cases of mitotic cells with low levels of labeling were observed, suggesting that during the five-hour pulse they were labeled just at the end of the S-phase and transited through G2/mitosis (Additional file 3).

There is a strong accumulation of EdU + cells in the brood capsule buds and in the protoscolex buds (Figure 2A and B). During early development, most EdU + cells do not reach the periphery of the bud (Figure 2B). This pattern becomes more distinct as development progresses, and when the main nervous commissure becomes evident by FMRFamide immunoreactivity [40] most EdU + cells are located posterior to it (Figure 2C). In the last stages of protoscolex development, there are some EdU + cells in the posterior body, while in the scolex, EdU + cells accumulate massively at the base of the developing suckers, but not in the rest of the sucker tissue (Figure 2D). Finally, cell proliferation becomes very low when protoscolex development is complete and the scolex is invaginated (Figure $2 \mathrm{~A}$ and $\mathrm{B}$ ). Identical results were obtained when metacestodes that had been cultured in vivo in gerbils were incubated with EdU ex vivo immediately after removing the material from the host

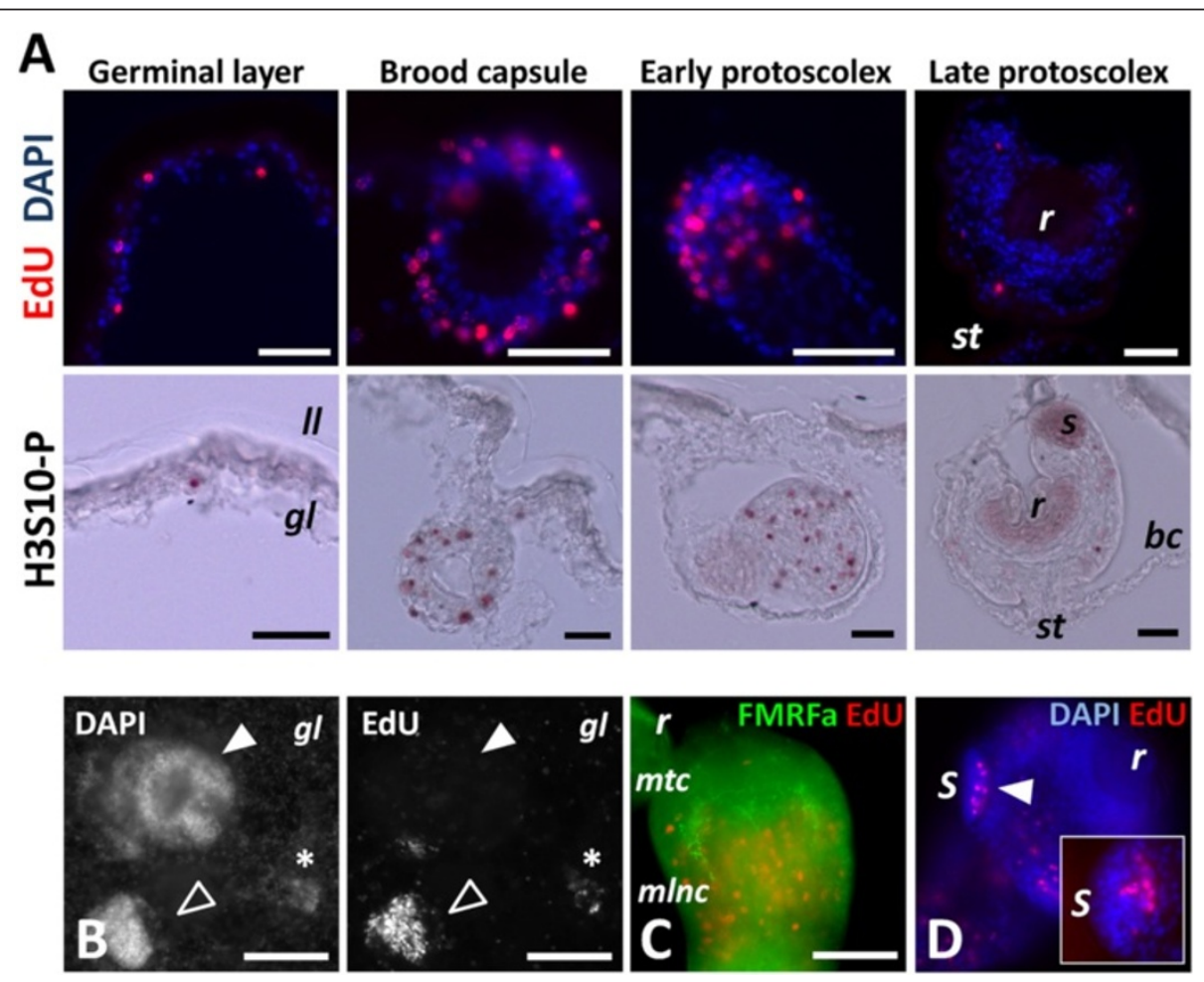

Figure 2 Cell proliferation in E. multilocularis metacestodes. (A) Detection of EdU incorporation and of H3S10-P in paraplast sections of different stages of development (some unspecific staining is seen in suckers and rostellum of protoscoleces for H3S10-P staining). (B) Whole-mount detection of EdU incorporation in a larval vesicle. The asterisk indicates an early brood capsule bud, the open arrowhead a brood capsule with a protoscolex bud, and the filled arrowhead an invaginated protoscolex. Notice also the dispersed EdU + cells in the germinative layer. (C) Whole-mount EdU detection (red) and FMRFamide immunofluorescence (green) during early protoscolex development. Most EdU + cells are located behind the main transverse commissure. (D) Whole-mount detection of EdU incorporation (red) during late protoscolex development. The arrowhead indicates the accumulation of EdU + cells at the base of the sucker. The inset shows EdU + cells in the base of a developing sucker as seen in a paraplast section. Abbreviations: bc, brood capsule; gl, germinal layer; ll, laminated layer; mlnc, main lateral nerve cord; mtc, main transverse commissure; $r$, rostellum or rostellum; s, sucker; st, stalk. Bars represent $30 \mu \mathrm{m}$ except for B, $100 \mu \mathrm{m}$. 
(Additional file 4), and similar patterns of cell proliferation have been described for protoscolex development in E. granulosus [37].

EdU incorporation remains very low for the first hours after protoscoleces are isolated from the metacestode material. However, when we activated protoscoleces by artificially mimicking the ingestion by the definitive host, the number of EdU + cells increased dramatically. Furthermore, prolonged in vitro culture of protoscoleces in the absence of activation factors also resulted in an increase of cell proliferation in many of them (Additional file 5). This indicates that in the developed protoscolex there is a large population of cells capable of proliferation, but they remain in a quiescent state or with slow cell-cycle kinetics for as long as the protoscolex remains resting within the metacestode.

As a complementary approach, we analyzed the distribution of mitotic cells by immunohistochemistry against histone H3 phosphorylated in Serine 10 (H3S10-P, [54]) after allowing the mitotic figures to accumulate by in vitro incubation with colchicine $[24,26]$. The distribution of H3S10-P + cells was identical to the distribution of $\mathrm{EdU}+$ cells, confirming the previous results (Figure 2A). The percentage of $\mathrm{H} 3 \mathrm{~S} 10-\mathrm{P}+$ cells in the germinative layer was low in the absence of colchicine incubation $(<0.5 \%$ of all cells), which suggests a fast transition through mitosis, as has been described in other cestodes $[22,55]$.

\section{Identification of germinative cells as the only proliferating cells}

Because of the small size of Echinococcus cells and the loose organization of the germinative layer, it is very difficult to identify cell types in situ by morphology except by means of electron microscopy $[28,56]$. In order to identify the EdU + cells, we performed a tissue maceration procedure that results in a suspension of cells that retain their original morphology [44,57-59]. We then stained these suspensions with 4',6-diamidino-2-phenylindole (DAPI, that specifically stains DNA) combined with propidium iodide (PI) or the Thermo Scientific Cellomics $^{\mathrm{Tm}}$ Whole Cell Stain (WCS) that stain all nucleic acids and are therefore analogous to the traditional Pyronin Y staining for basophilic, RNA-rich cells [26]. In parallel, we performed staining of cell suspensions for lipids using Nile red (NR) combined with DAPI (Figure 3).

With this method, we consistently identified the germinative cells as small ( 5 to $12 \mu \mathrm{m}$ across the longest axis), pear-shaped to fusiform cells that are strongly stained with PI and WCS, and that can sometimes have thin cytoplasmic extensions protruding from the poles. The nucleus is round and very large, with one to three very prominent nucleoli and with finely granular chromatin, giving a very bright staining with DAPI. Cytoplasmic lipid droplets were rare.
The germinative cells were the only cells that incorporated EdU after two to six hours of incubation in vitro ( $\mathrm{n}=5$ independent labeling experiments): after five hours of labeling, an average of $24 \% \pm 6.7 \%$ (standard deviation) of the germinative cells were EdU +. Germinative cells were also the only cells observed in mitosis. Size differences were observed between these cells, and smaller germinative cells were less likely to incorporate EdU (Additional file 6), suggesting that cell size may be related in part to different cell-cycle phases. In small metacestode vesicles, the germinative cells were on average $21 \%$ of all the cells. We observed that in larger vesicles, the apparent abundance of the germinative cells was higher, up to around $50 \%$ of all cells. However, in these vesicles the tissue maceration was incomplete, and we believe that the germinative cells were overrepresented in the cell suspensions. Indeed, taking into account that in whole-mounts of these vesicles an average of $5.9 \%$ of all cells were EdU +, and that $24 \%$ of all germinative cells are EdU + in the cell suspensions, by assuming that all EdU + are germinative cells (see above) one can approximately estimate the fraction of germinative cells as $25 \%$ of all cells. In activated protoscoleces, although the tissue maceration was incomplete as well, we also observed germinative cells as the only EdU + cells after a five hour pulse (Additional file 7).

All morphologically differentiated cells were consistently EdU -, indicating that they are generated by differentiation of the proliferating germinative cells. Among the differentiated cells, we could recognize several types by comparison with ultrastructural descriptions from E. multilocularis metacestodes and classic histological studies in other cestodes $[23,28,39,58]$ (Figure 3). These included: 1) the tegumental cells, with abundant cytoplasm strongly stained with PI/WCS, uniformly stained by NR, and with an irregularly shaped border. The nucleus can be slightly irregularly shaped and shows chromatin clumps in the periphery; 2) the glycogen/lipid storage cells. These cells have large and smooth cytoplasmic lobes, show very low staining with PI/WCS, and have lipid droplets as seen by NR staining; 3) the calcareous corpuscle forming cells, with a small and eccentric nucleus and a large round cytoplasm that shows little staining for PI, WCS or NR; 4) several small cell types with a small, heterochromatin-rich nucleus. It is likely that muscle cells and nerve cells are found in this category after losing their cytoplasmic extensions during the maceration procedure.

In order to confirm that the differentiated cell types are generated from the pool of proliferating germinative cells, we performed EdU pulse-chase assays, in which we incubated the vesicles for two hours with $50 \mu \mathrm{M}$ to $100 \mu \mathrm{M}$ EdU, followed by washing and incubation in EdU-free medium for up to seven days. Unfortunately, 


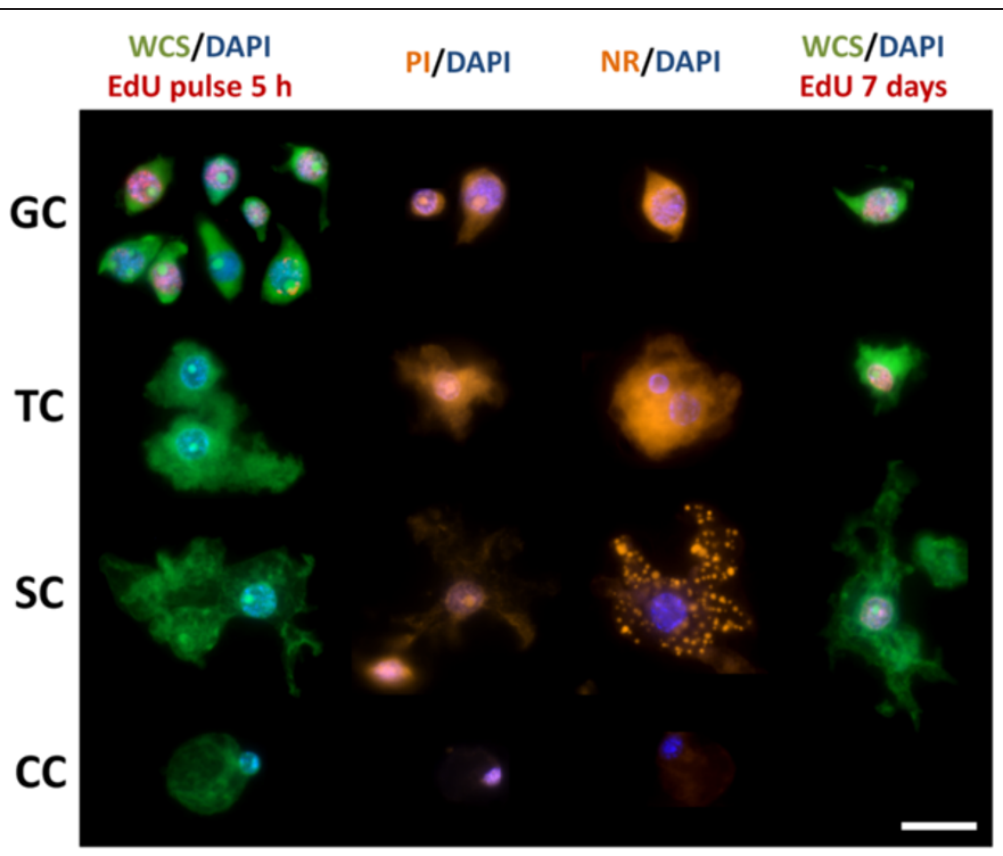

Figure 3 Cell suspensions of Echinococcus multilocularis. This is a montage of images of different cell types as observed in cell suspensions after different staining procedures. Cell types are indicated on the left (GC: germinative cells; TC, tegumental cells; SC, glycogen/lipid storage cells; CC, calcareous corpuscle cells) and staining procedures are indicated on top (NR, Nile red, shown in orange; PI, propidium iodide, shown in orange; WCS, whole cell staining, shown in green), including the detection of EdU (shown in red) after two different labeling treatments, $50 \mu \mathrm{M}$ for five hours and 1 to $10 \mu \mathrm{M}$ for seven days (see the main text for details). The bar represents $10 \mu \mathrm{m}$.

we observed that the EdU signal was stronger after a three-day chase period than directly after the pulse (data not shown), indicating that EdU remains in the hydatid fluid after washing. As a complementary approach, we performed continuous EdU labeling experiments with $1 \mu \mathrm{M}$ to $10 \mu \mathrm{M}$ EdU for up to 14 days. In this setting, we observed that the higher concentrations $(10 \mu \mathrm{M})$ showed some toxicity in this setup, whereas lower concentrations $(0.5 \mu \mathrm{M})$ did not yield cells with enough labeling for detection. In both pulse-chase and continuous labeling experiments, we observed EdU + tegumental and glycogen/lipid storing cells after seven days (Figure 3 and data not shown), suggesting differentiation of germinative cells into these cell types. In summary, we identified the germinative cells as the only proliferating cell population, and the evidence suggests that differentiated cell types are generated from the germinative cells.

\section{Gene expression patterns in the germinative cells}

To identify genes that are specifically expressed in the germinative cells, we analyzed the expression of several candidate genes among planarian neoblast markers by whole-mount in situ hybridization (WMISH).

\section{em-h2b}

As a possible general marker of all proliferating germinative cells, we analyzed the expression of histone
H2B homologs, since canonical histones are synthesized in a cell-cycle dependent manner: histone transcripts only accumulate during the S-phase, when new histones are needed to accompany the synthesis of DNA [60]. Furthermore, H2B genes have been found to be specifically expressed in proliferating planarian neoblasts and in the neoblast-like cells of the trematode Schistosoma mansoni $[61,62]$.

Several canonical H2B genes are present in the E. multilocularis genome. Most of them are almost identical to each other ( $>95 \%$ nucleotide identity), which we denominate the $e m-h 2 b-1$ group. Another gene, $e m-h 2 b-2$, also shows high amino acid identity (97\%) but lower nucleotide identity (85\%) to $e m-h 2 b-1$. Using probes for $e m-h 2 b-1$ and $e m-h 2 b-2$ gave identical results, which were indistinguishable from the EdU labeling pattern in the germinal layer and throughout the development of brood capsules and protoscoleces (Figure 4). This is particularly striking during late protoscolex development, where a massive accumulation of $e m-h 2 b+$ cells is found at the base of the suckers but no expression is seen in the remaining sucker tissue (Figure 4E).

The WMISH signal labeled the cytoplasm of cells with the typical germinative cell morphology (Figure 4B). Furthermore, when combining WMISH with EdU detection after a five hour pulse, $78 \%$ of all $e m-h 2 b+$ cells were also EdU $+(\mathrm{n}=197 h 2 b+$ cells $)$, and conversely, $87 \%$ of 

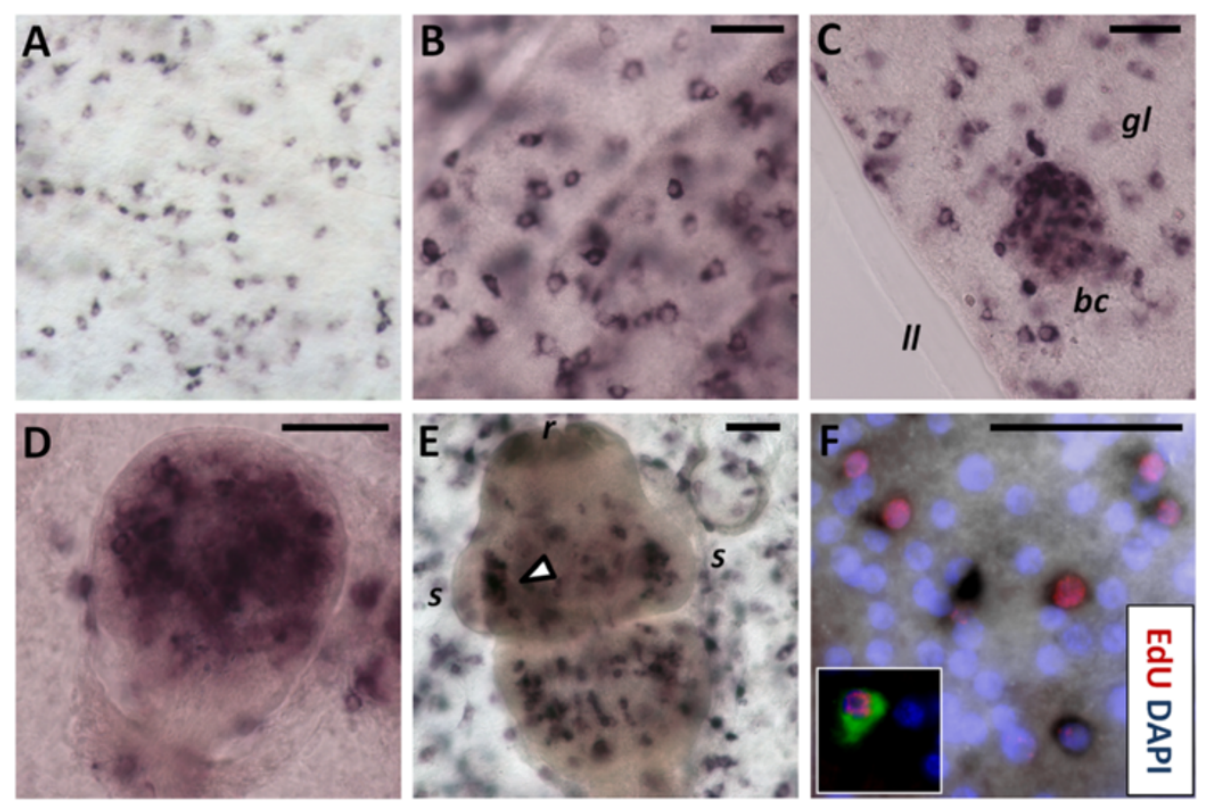

Figure 4 WMISH detection of $\mathbf{e m}-\boldsymbol{h} \mathbf{2} \boldsymbol{b}$. (A) General view of the germinal layer. (B) Detail of the germinal layer; showing the germinative cell morphology of the positive cells. (C) Early brood capsule bud. (D) Protoscolex bud. (E) Late protoscolex development. The arrowhead indicates the accumulation of positive cells at the base of the sucker. (F) Co-localization of em-h2b (dark precipitate) and EdU detection (red) after a $50 \mu \mathrm{M}$, five hour pulse. The inset shows an example in which the em-h2b signal was inverted and pseudo-colored in green to facilitate the visualization of the co-labeling. Abbreviations are as in Figure 2. Bars represent $25 \mu \mathrm{m}$.

all EdU + cells were also $e m-h 2 b+(\mathrm{n}=176 \mathrm{EdU}+$ cells $)$ (Figure 4F). Because only germinative cells proliferate (see above), em-h2b is therefore a bona fide marker of S-phase germinative cells, but would not detect resting or G1 and G2/M germinative cells. The smaller proportion of EdU $-h 2 b+$ cells had probably already entered $\mathrm{S}$-phase but were fixed before enough EdU was incorporated for detection, while the EdU $+h 2 b$ - cells were probably fixed after they had already incorporated EdU but exited the S-phase during the incubation time.

\section{em-nos-1 and em-nos-2}

We then turned to possible post-transcriptional regulators of the germinative cells. nanos genes are molecular markers of the germ line in many classical models, but are also expressed in multipotent stem cells in various basal metazoan lineages $[11,19,63,64]$. Two nanos genes are present in E. multilocularis (em-nos-1 and em-nos-2). Both genes were expressed in few cells with a patchy distribution in the germinal layer (Figure 5A and D), and with the morphology of large germinative cells $(<1.6 \%$ of all cells for both em-nos-1 and em-nos-2, $\mathrm{n}=4,632$ cells and $n=7,475$ cells, respectively; Figure $5 B$ and $E$ ). Furthermore, em-nos-1 and em-nos-2 cells can incorporate EdU (19\% of em-nos 1+ cells are EdU + after a five hour pulse, $n=96$ ), although the vast majority of EdU + cells do not express either gene $(<5 \%$ of all EdU + cells express either nanos gene, Figure $5 \mathrm{C}$ and F). Altogether, these data show that a small subpopulation of the germinative cells in the germinal layer express em-nos-1 and em-nos-2, although it is not clear if both genes are co-expressed in the same cells.

During brood capsule and protoscolex development, em-nos-1 expression was not detected. Expression of em-nos-2 was sometimes seen around brood capsule buds, and later during early protoscolex development as a small population of cells at the base of the protoscolex bud (Figure 5G and H). Finally, em-nos-2 is expressed in a few cells associated with the developing nervous system, in the region of the developing lateral ganglia and the main commissure (Figure 5I). These results show that most proliferating cells do not express nanos genes in the developing protoscolex, and suggest a role for emnos-2 during nervous system development.

\section{em-ago2}

Although piwi genes are not present in E. multilocularis, there are other argonaute proteins encoded by the genome: an ortholog of human Ago-1-4 proteins which is likely involved in RNA interference (EmAgo1 [65]) and three copies of an Argonaute gene family that is specific for cestodes and trematodes [38], which we dubbed emago2- $A$ to em-ago2-C. We further identified a pseudogene, em-ago2- $\Psi$ (Additional file 8). These copies have resulted from a recent duplication that occurred after the divergence of Hymenolepis and -Echinococcus + 


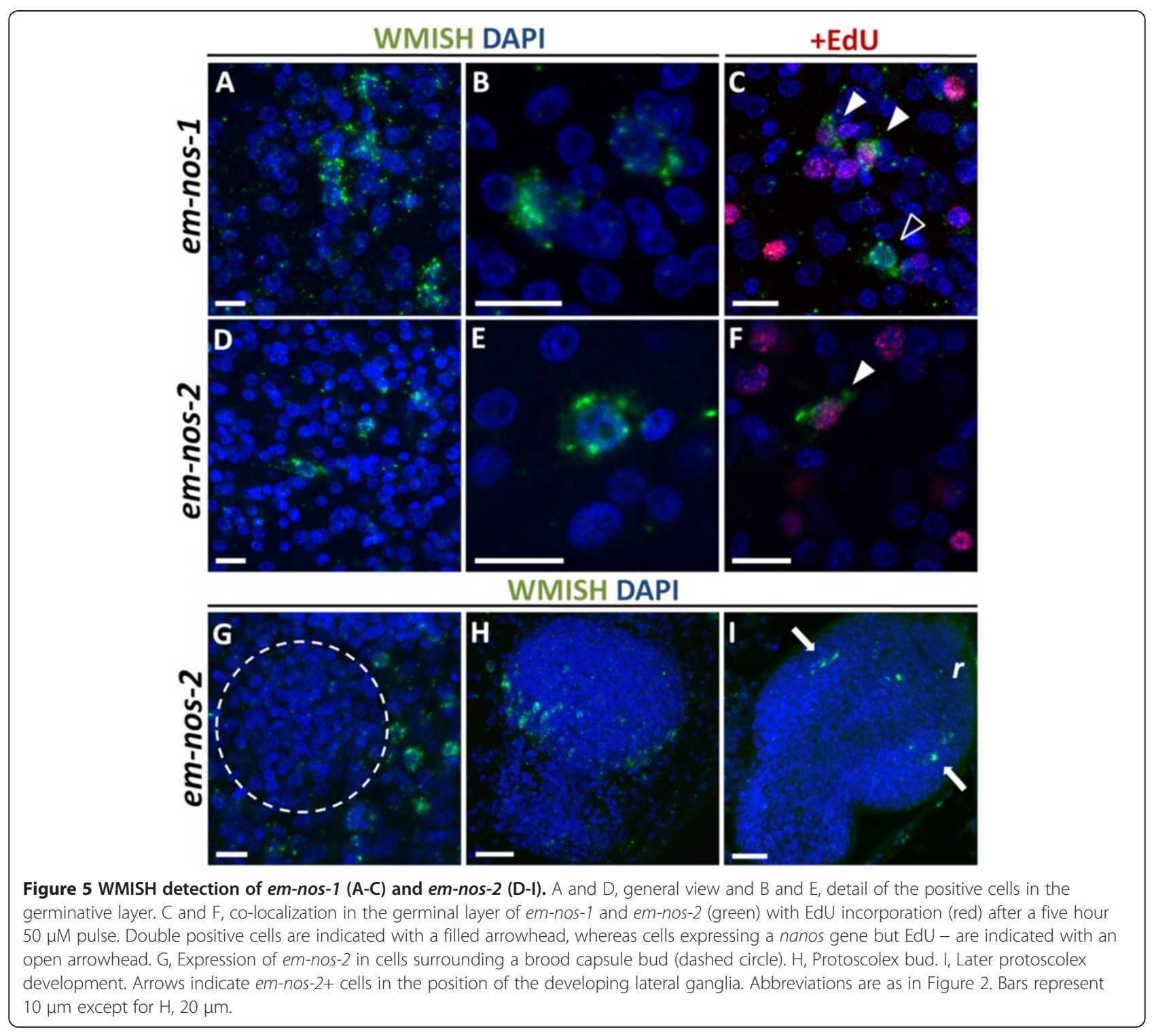

Taenia- (see the phylogenetic analyses in [38]), with 88 to $99 \%$ nucleotide sequence identity between copies (depending of the copies and the specific regions compared). Moreover, they are organized as two couples of tandemly arranged copies in close proximity to a copy of a Sec61 homolog (Additional file 8). This conservation of synteny suggests that one first duplication occurred which resulted in two adjacent copies of an original em-ago2 gene located next to a $\operatorname{Sec} 61$ gene, followed by the duplication of the whole region. Long-range PCR with genomic DNA confirmed the organization of these genomic regions (Additional file 8), while sequencing of smaller PCR fragments confirmed the existence of all four copies, demonstrating that they are not an artifact of genome assembly. By RT-PCR only em-ago2- $A$, em-ago2-B and em-ago2- $\Psi$ mRNA could be detected, whereas em-ago2- $C$ was absent or barely detected in all of the larval stages and in primary cell cultures.

We performed WMISH using two different probes for em-ago2- $A$. These probes would probably cross-react with all other em-ago 2 copies, and we refer to the expression pattern of all these genes by the collective name em-ago2. em-ago 2 expression was similar to the pattern of EdU incorporation in the germinal layer, and cells strongly expressing em-ago2 accumulate in the brood capsules and protoscolex buds (Figure 6A to $\mathrm{C}$ ). The distribution of the em-ago 2 signal within cells is very distinct since it is only observed close to or within the nucleus (Figure 6A). Strongly positive em-ago2+ cells account for approximately $30 \%$ of all cells in the germinal layer, but notably, some expression of em-ago2 was observed in more than $50 \%$ of all cells, indicating that it is not exclusive to the germinative cell population. 

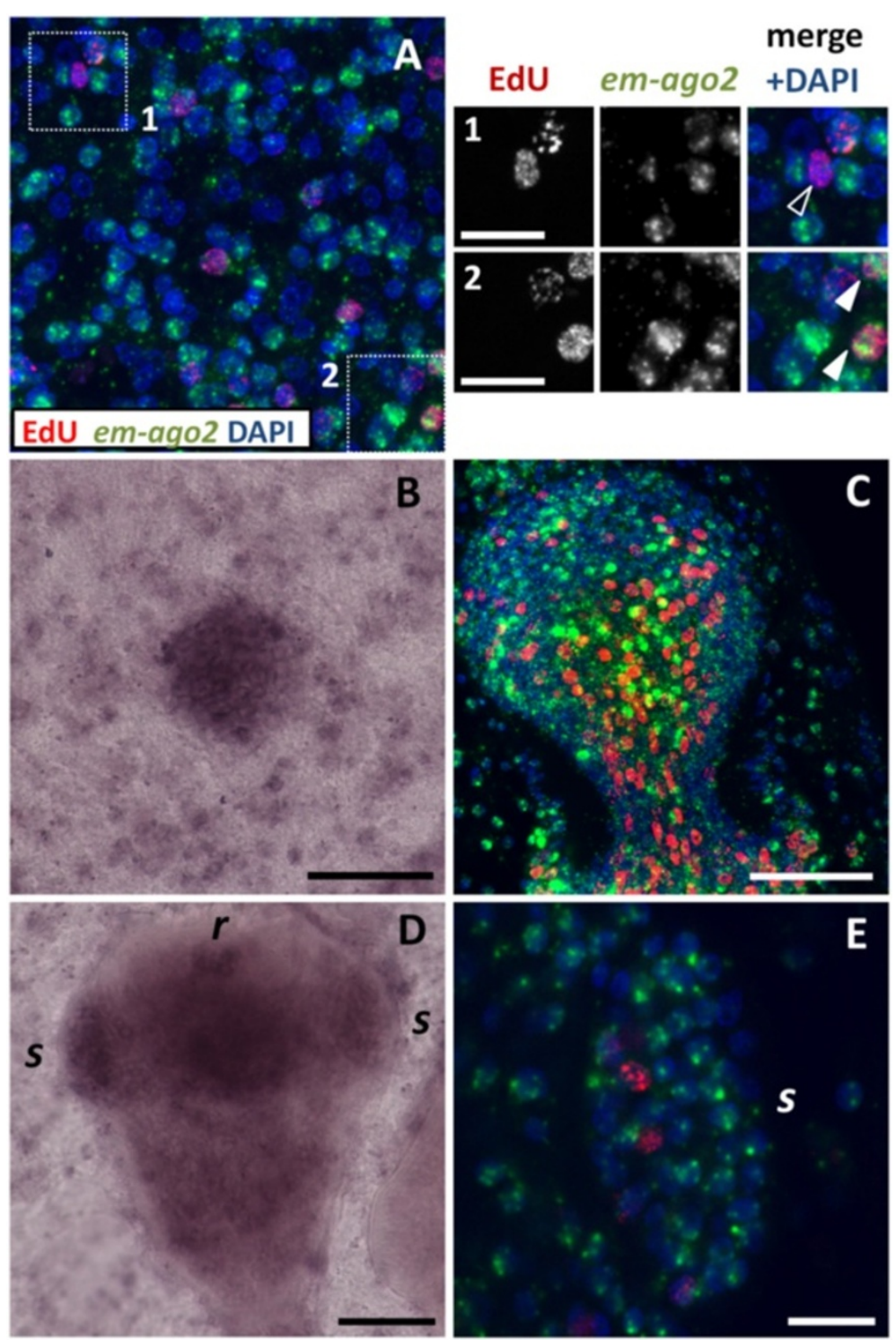

Figure 6 WMISH detection of em-ago2. (A) General view of the germinal layer. The insets show details of EdU + em-ago2 cells (open arrowheads) and EdU + em-ago2+ cells (filled arrowheads) after a five hour, $50 \mu \mathrm{M}$ EdU pulse. (B) Early brood capsule bud. (C) Protoscolex bud; colors are coded as in Figure 5A. (D) Late protoscolex development. (E) Detail of a sucker from a protoscolex in late development, showing that em-ago2 expression is not restricted to the base; colors are coded as in Figure 5A. Abbreviations are as in Figure 2. Bars represent $10 \mu \mathrm{m}$ in A1 and $\mathrm{A} 2$, and $40 \mu \mathrm{m}$ in all other panels.

There is no clear-cut correlation between the level of em-ago 2 expression and proliferation, since approximately $50 \%$ of EdU + cells show low or no expression of em-ago2 (Figure 6A). Conversely, during early protoscolex development, it is clear that although em-ago2 expression is present in most cells, the cells with the strongest em-ago2 signal are almost invariably EdU(Figure 6C). During late protoscolex development, some em-ago2 signal is observed in most cells (Figure 6D and $\mathrm{E}$ ), and is not restricted to the base in the suckers (where cell proliferation occurs). It is therefore clear that the expression of em-ago2 is not restricted to proliferating cells. Moreover, the expression of em-nos-1, em-nos-2 and em-ago 2 point to extensive heterogeneity at the molecular level among the proliferating germinative cells.

\section{em-hdac1 and em-phb1}

The histone deacetylase HDAC1 is one of many chromatin modifying proteins that are specifically expressed in planarian neoblasts $[15,66]$. Neoblast specific expression has also been shown for the mRNA of homologs of prohibitin-1 and prohibitin-2 [15,16]. In mammalian cells, prohibitins form complexes in the inner mitochondrial membrane with unclear biochemical function, and 
have been linked to mitochondrial biogenesis and cell proliferation [67].

We found single-copy orthologs of HDAC1 (em-hdac1) and prohibitin-1 (em-phb1) in the E. multilocularis genome, and both genes showed widespread expression in the germinal layer and during protoscolex development (Additional files 9 and 10). We also determined the distribution of the Em-PHB1 protein by immunohistochemistry, and compared this to the distribution in planarian tissues using a commercial antibody that recognizes a conserved region in all PHB1 proteins. In planarians, although low levels of PHB1 are seen in post-mitotic tissues such as the pharynx, the highest signal is observed in neoblast-like cells in the mesenchyma (Additional file 11). In contrast, E. multilocularis Em-PHB1 is observed throughout the germinal layer, brood capsules and developing protoscoleces (Additional file 12). In summary, neither gene has a germinative cell specific expression in E. multilocularis metacestodes.

\section{Identification of molecular markers for differentiated cell types}

The identification of differentiated cell types in the germinal layer is difficult, and unlike the situation in adult cestodes, trematodes and planarians, the lack of spatial segregation of any post-mitotic cell types makes it impossible to trace the differentiation of germinative cells in situ. Therefore, we set out to find molecular markers of differentiated cell types in Echinococcus.

\section{em-muc-1 and em-alp-2 as tegumental cell markers}

Since the laminated layer is synthesized by the tegumental syncitium, genes coding for laminated layer components should be expressed by the tegumental cells [68]. We analyzed the expression of em-muc-1, a member of an Echinococcus-specific, highly expressed apomucin gene family that has been proposed to be a main component of the laminated layer $[38,68,69]$. Because all members are very similar (with regions with over 90\% identity at the nucleotide level) it is likely that the $\mathrm{em}$ muc-1 probe recognizes most genes of this gene family.

em-muc-1 is strongly expressed in the germinal layer but not in protoscoleces, as is expected for a component of the laminated layer (Figure 7A). em-muc-1 was expressed in cells with abundant cytoplasm that fuse or interdigitate with each other, and which constitute 27 to $37 \%$ of all cells in the germinative layer (two independent WMISH experiments; $\mathrm{n}=3,440$ and 780 cells, respectively; Figure 7B). In stark contrast, no expression is observed in early brood capsule buds or in developing protoscoleces. To our surprise, however, we could detect low levels of em-muc-1 in late brood capsules, which suggests that the glycocalix of the brood capsule may also contain the product of em-muc-1, although the laminated layer does not line the brood capsule cavity [68] (Figure 7D). By combining WMISH with EdU detection, we observed the absence of EdU + cells among the em-muc-1+ cell population $(\mathrm{n}=1,454$ em-muc-1+ cells from two independent WMISH experiments; Figure $7 \mathrm{C}$ ). We conclude that em-muc-1 is a robust marker for tegumental cells in the germinal layer, and confirm that the tegumental cell population does not proliferate.

While searching for possible histochemical markers, we observed that alkaline phosphatase activity in the metacestode is very high (strong reaction in less than five minutes) and restricted to the distal syncitial tegument of the germinal layer (Figure 8A; see also [70]), but is not found in brood capsules (Additional file 13). This indicated that one or more alkaline phosphatase genes must be expressed in the tegumental cells. In protoscoleces, alkaline phosphatase was detected only after several hours, and only in the excretory system (Figure $8 \mathrm{~B}$ ), similar to what has been described in the developing adult [71]. This activity increased after protoscolex activation (Additional file 13). Four genes encoding alkaline phosphatases (em-alp-1 to em-alp-4) were found in the E. multilocularis genome. By RT-PCR, em-alp-1 and em$a l p-2$ were found to be specifically expressed in the germinal layer, while em-alp-3 was only detected in protoscoleces, with a strong up-regulation after protoscolex activation (Figure 8C). em-alp-4 has substitutions of conserved catalytic amino acid residues, and no expression was detected by RT-PCR in the germinal layer or in protoscoleces, suggesting that it is a pseudogene, although expression was observed in high throughput RNA sequencing data of adult worms [38]. Altogether, the data suggested that em-alp-1 and em-alp-2 were expressed in the tegumental cells of the germinal layer, while em-alp-3 was expressed in the protoscolex excretory system, and is to the best of our knowledge the first gene shown to be up-regulated after protoscolex activation. We therefore analyzed the expression pattern of em-alp-2 by WMISH, and found it to be identical to that of em-muc-1 in the germinal layer, with no expression in the brood capsule buds or in the developing protoscoleces (Figure 8D). In conclusion, em-alp-2 is another marker for the tegumental cells in the germinal layer.

\section{Acetylated tubulin a as a marker of nerve cells}

We have recently shown that a net of nerve cells in the germinal layer can be detected by immunohistofluorescence against acetylated tubulin $\alpha$ (AcTub + cells, [40]). Here, we show that the nerve cells do not proliferate, since they are EdU - after a five hour, $50 \mu \mathrm{M}$ EdU pulse ( $\mathrm{n}=$ 874 AcTub + cells from three independent experiments; Additional file 14). Similarly, in activated protoscoleces all AcTub + cells (including in this case both nerve cells and flame cells [40]) were EdU - (data not shown). 


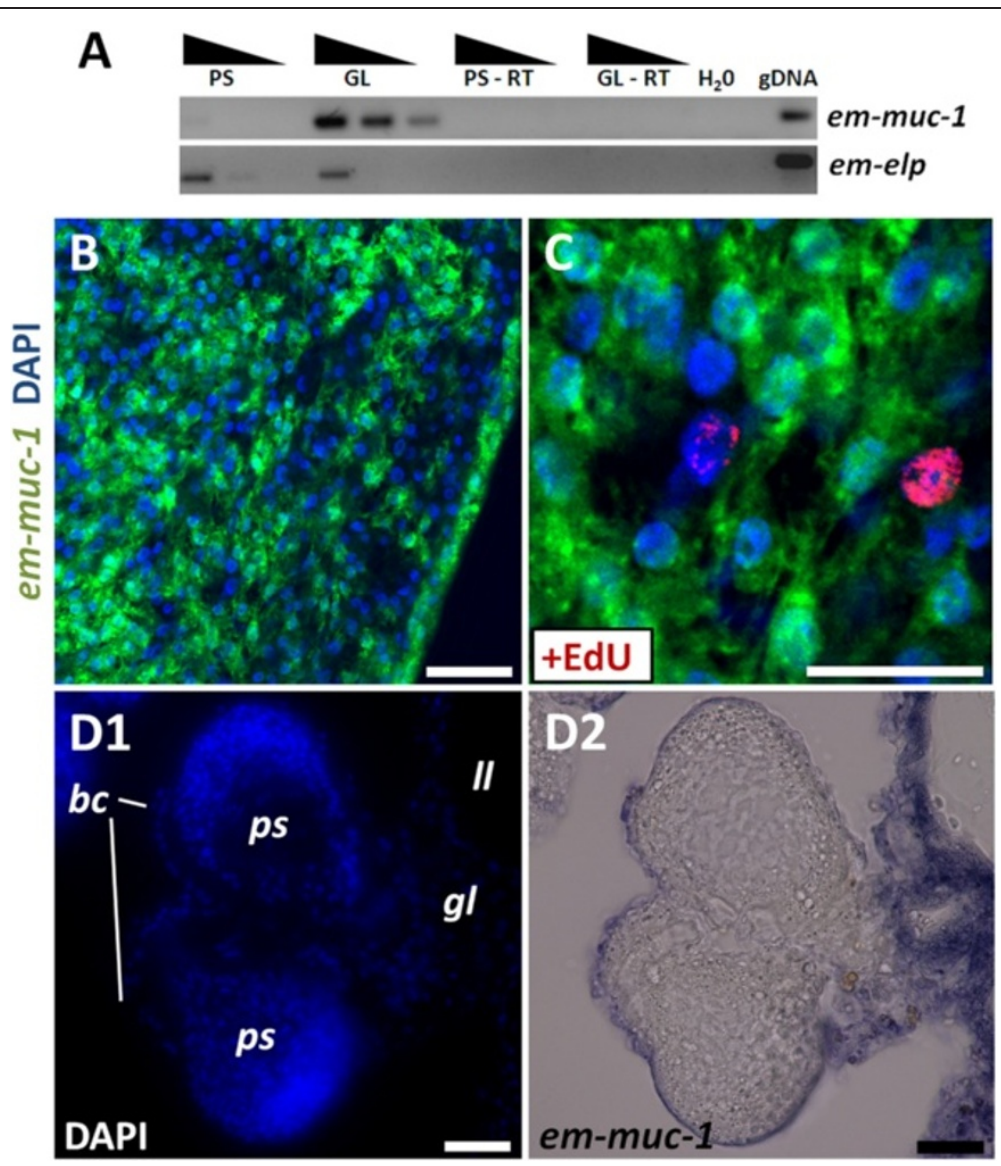

Figure 7 Expression of em-muc-1. (A) Semi-quantitative RT-PCR with serial ten-fold dilutions of cDNA from protoscoleces (PS) and germinal layer (GL). Controls without reverse transcriptase (RT) and without template $\left(\mathrm{H}_{2} \mathrm{O}\right)$ are included. (B-D) WMISH of em-muc-1. (B) General view of the germinal layer. (C) Double detection of WMISH (green) and EdU incorporation after a five hour, $50 \mu \mathrm{M}$ EdU pulse (red); note the lack of EdU labeling among the em-muc-1+ cells. (D1 and D2) Section of metacestode processed for WMISH, showing the lack of expression in the developing protoscoleces, strong expression in the germinal layer, and expression in the brood capsule wall. Abbreviations are as in Figure 2. Bars represent $20 \mu \mathrm{m}$ except for $\mathrm{B}, 10 \mu \mathrm{m}$.

We performed a quantitative analysis of the formation of new AcTub + cells by determining the percentage of EdU + AcTub + cells during continuous EdU labeling. No double labeled cells were observed after seven days, but the percentage increased to $13.3 \%$ after 14 days (Additional file 14). Because no EdU incorporation was observed in nerve cells even after seven days of continuous exposure, this strongly indicates that all EdU + nerve cells must originate from the differentiation of proliferating germinative cells, which would require more than seven days after exiting the cell cycle to become AcTub+. Higher concentrations of EdU $(10 \mu \mathrm{M})$ apparently had a toxic effect, and only $2.8 \%$ of the AcTub + cells were EdU + after 14 days (Additional file 14).

\section{em-tpm-1.hmw as a marker for muscle cells during protoscolex development}

Using a specific antibody that recognizes the high molecular weight (HMW) isoforms of two tropomyosin genes from cestodes (tpm-1 and tpm-2), HMWtropomyosins have been shown to be present exclusively in the muscle fibers in the cestode Mesocestoides corti, and are strongly expressed in the suckers of E. granulosus protoscoleces $[49,50]$. Using this antibody, we confirmed that HMW tropomyosin isoforms can be found in the muscle fibers in the germinal layer, accumulating in the interior of brood capsules and in the muscle layers during protoscolex development in E. multilocularis (Additional file 15), in perfect correlation to the description of muscle fibers as determined by phalloidin labeling [40].

Because in cestodes the nucleus of muscle cells is located in a non-contractile cell body, connected by thin cytoplasmic bridges to the contractile myofibers [72,73], it is not possible to identify the cell bodies by immunodetection of HMW-tropomyosins. Instead, we analyzed the expression of the HMW isoform of em-tpm-1 by WMISH using a specific probe. Surprisingly, no expression 


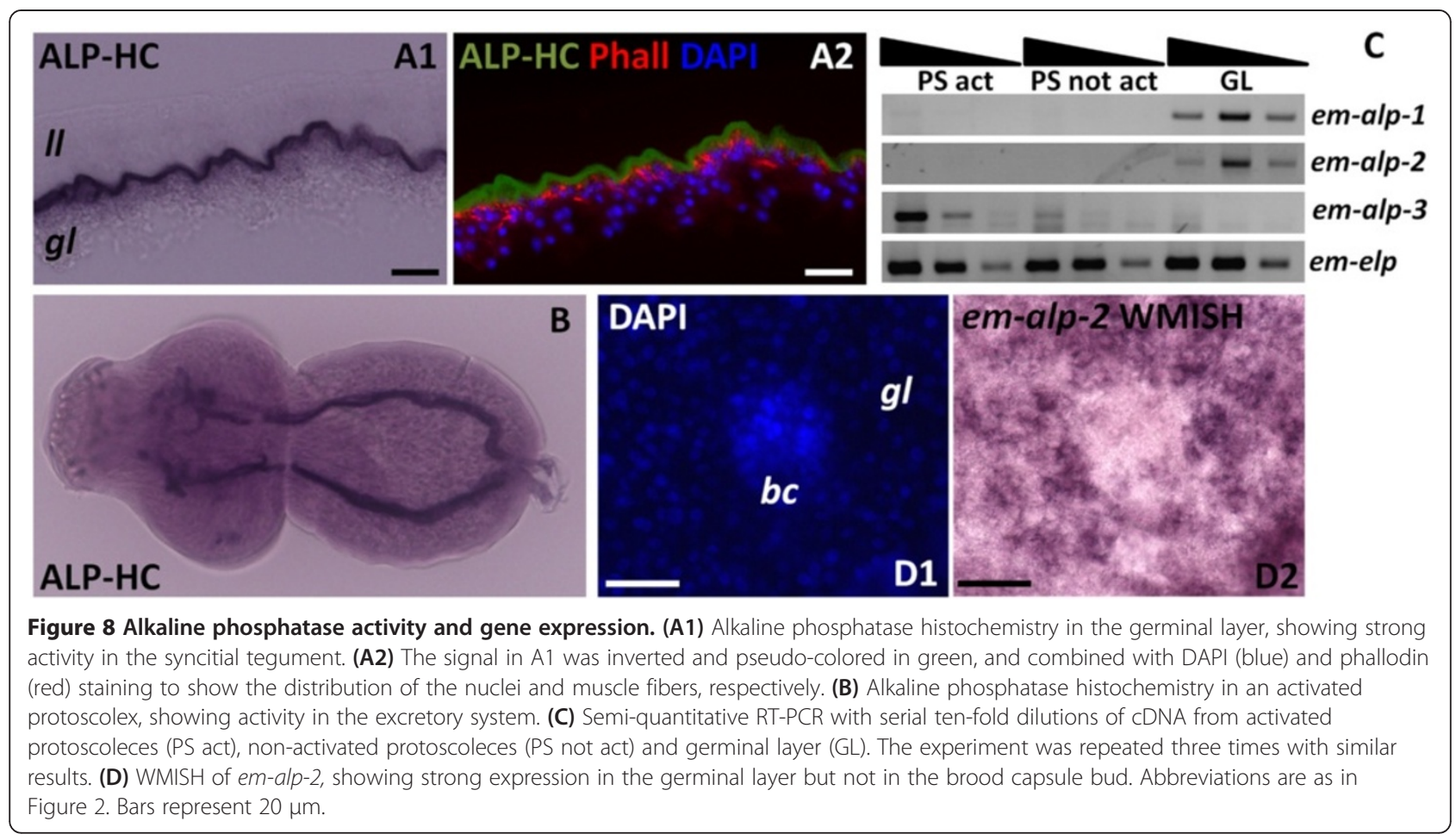

was observed in the germinal layer, suggesting that muscle cells in this tissue express other tropomyosin isoforms (that is from em-tpm-2). Instead, em-tpm-1.hmw was detected in individual cells in the center of invaginating brood capsules (Figure 9A), in close proximity to the location of muscle fibers [40]. During early protoscolex development, when muscle development is already underway [40], emtpm-1.hmw is expressed in two symmetrical bands of superficial cells and one internal medial band (Figure 9B). Because of their distribution, these are likely to be the subtegumental circular muscle cells and the inner longitudinal muscle cells. Finally, strong expression was observed in the muscular suckers and rostellum and in individual cells in the body of the developed protoscolex (Figure 9C). In summary, em-tpm-1.hmw can be used as a molecular marker for the development of muscle cells during brood capsule and protoscolex development, but not in the germinal layer.

Partial depletion of germinative cells by irradiation and hydroxyurea treatments

Total and partial elimination of neoblasts by irradiation has been a powerful tool for studying neoblast gene expression and physiology in many flatworms $[7,13,15,16,62,74,75]$. In E. multilocularis, comparable doses of ionizing radiation (50 to $100 \mathrm{~Gy}$ ) were found to only retard growth of metacestodes, and did not eliminate the germinative cells [76]. We performed similar experiments with a single X-ray irradiation dose of 150 Gy on metacestode vesicles (lacking brood capsules and protoscoleces). At 48 hours postirradiation, we observed that the number of cells incorporating EdU per area of germinative layer decreased in

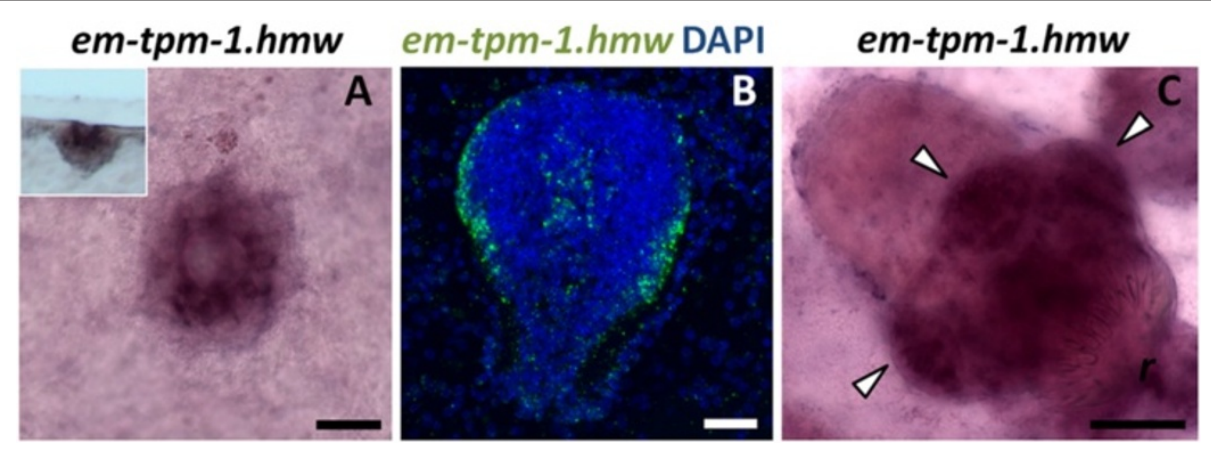

Figure 9 WMISH detection of em-tpm-1.hmw. (A) Early brood capsule bud as seen from above. The inset shows a lateral view. (B) Protoscolex bud. (C) Developed protoscolex. The arrowheads point to the suckers. Abbreviations are as in Figure 2. Bars represent $20 \mu \mathrm{m}$ (A, B) or $40 \mu \mathrm{m}$ (C). 
average to $22 \%$ of unirradiated controls, showing that very high dosages of X-ray irradiation decrease but are unable to eliminate all proliferating cells (Figure 10A). Interestingly, we observed no significant increase in the number of EdU incorporating cells for up to 48 days post-irradiation, and the number of EdU + cells per area was still on average only $28 \%$ that of unirradiated controls (Figure 10A). Despite this long-term decrease in cell proliferation, no difference in survival was observed between irradiated and unirradiated metacestodes after 48 days (82\% versus $86 \%, P=0.49$, Chi-square test).

As an alternative approach, we used hydroxyurea (HU), an inhibitor of ribonucleotide reductase (RRM) that is specifically toxic to cells undergoing DNA synthesis during cell proliferation [77-79], and which has also been used in other invertebrates to eliminate stem cells $[75,80,81]$. The mechanism of toxicity is based on the depletion of deoxyribonucleotide triphosphates (dNTPs) that results from RRM inhibition, provoking the cessation of DNA replication and thus leading to stalled replication forks and eventually to chromosomal DNA damage [82]. In order to confirm a similar effect of $\mathrm{HU}$ on E. multilocularis cells, we incubated primary cell cultures with different $\mathrm{HU}$ concentrations. Indeed, incorporation of the thymidine analog 5-bromo-2'-deox-
yuXridine (BrdU) was reduced by approximately $50 \%$ and $90 \%$ in the presence of $10 \mathrm{mM}$ and $40 \mathrm{mM} \mathrm{HU}$, respectively. Furthermore, the regeneration of metacestode vesicles from primary cells was strongly decreased by 10 $\mathrm{mM} \mathrm{HU}$ and abolished by $40 \mathrm{mM} \mathrm{HU}$ (Additional file 16).

We therefore incubated metacestode vesicles (lacking brood capsules and protoscoleces) with $40 \mathrm{mM} \mathrm{HU}$ for seven days, and allowed them to recover in $\mathrm{HU}$-free media for 24 hours. This resulted on average in a $90 \%$ reduction in the number of cells incorporating EdU per area of germinative layer (Figure 10B). Furthermore, the experimental results could be divided into two groups: Group 1, from experiments performed on larger and older vesicles, resulted in a decrease of only $66 \%$ to $93 \%$ in the number of EdU + cells (similar to the results observed after X-ray irradiation), whereas Group 2, performed in smaller and younger vesicles, resulted in a greater decrease of $97.7 \%$ to $99.8 \%$ of EdU + cells with respect to the non-treated controls.

We analyzed in detail the effect of HU on the metacestode vesicles. Quantification of germinative cells in tissue macerates showed that the loss of EdU + cells was paralleled by a decrease in germinative cells, from 20 to $22 \%$ to 3 to $5 \%$ of all cells (two independent experiments, $P \leq 0.001$ for both, Chi-square test). However,

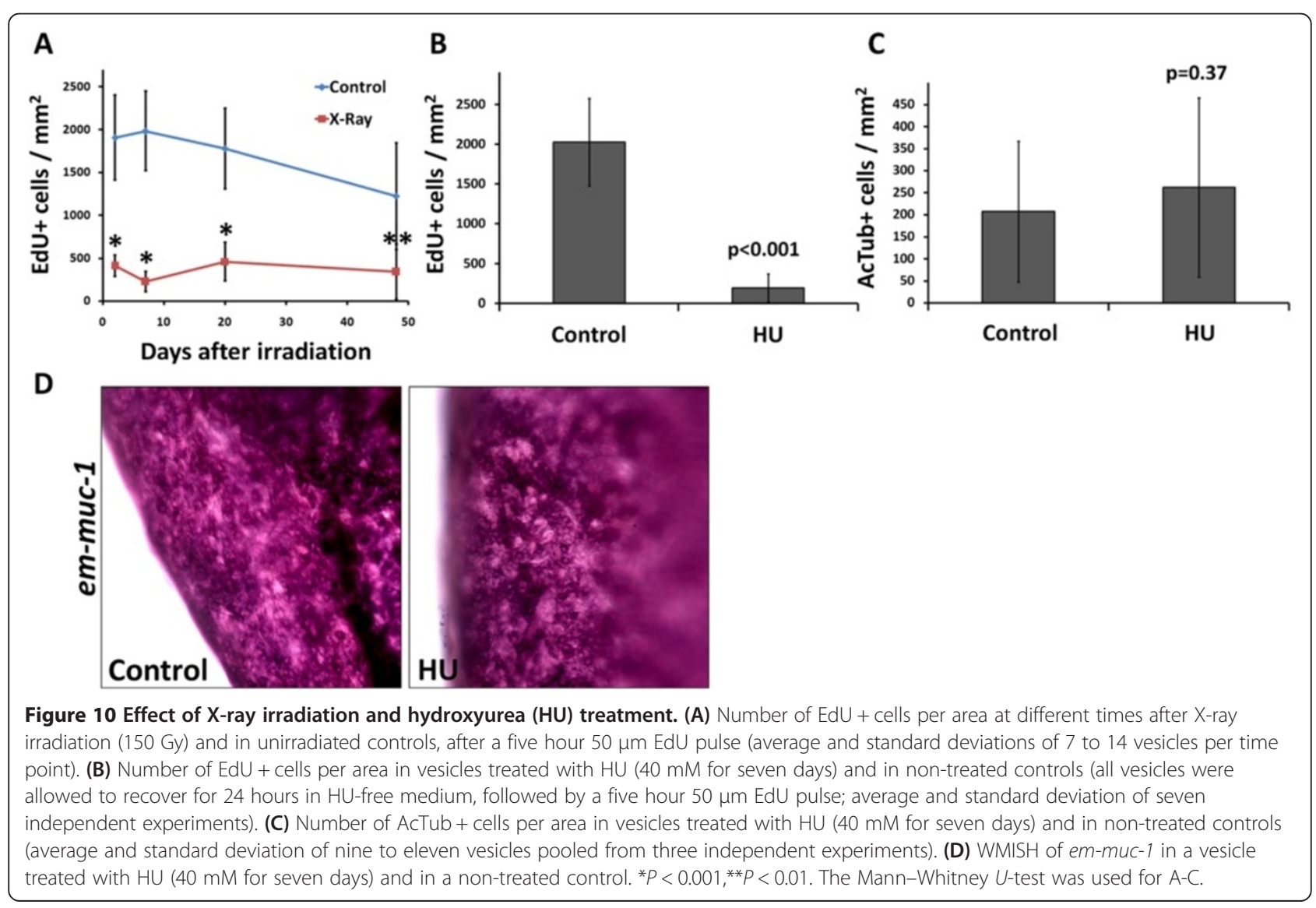


differentiated cells did not seem to be affected by the $\mathrm{HU}$ treatment: nerve cell numbers per area of germinative layer were not significantly reduced, as determined by AcTub immunohistofluorescence (Figure 10C) and the tegumental cell marker $e m-m u c-1$ showed a qualitatively similar expression pattern in both conditions (Figure 10D). We conclude that HU treatment for seven days specifically depletes the germinative cell population, with little effect on the number of differentiated cells.

Prolonged times of recovery of vesicles from Group 1 in HU-free media did not result in a significant increase of EdU + cells after up to 22 days, similar to the results obtained after X-ray irradiation. However, in Group 2, we could observe highly localized, time-dependent increments in the number of EdU + cells, strongly suggestive of clonal growth from surviving proliferating cells (Figure 11). In most experiments, only isolated EdU + cells could be found after one day of recovery. As recovery time increased, patches of two EdU + cells (after one to four days of recovery), three to four EdU + cells (after four to nine days of recovery) and of more than thirty $\mathrm{EdU}+$ cells (after nine days of recovery) could be found in some of the metacestode vesicles. This strongly indicates the existence of cells in the metacestode (presumably germinative cells) that can respond to the substantial depletion of proliferating cells by undergoing self-renewing divisions into proliferation-competent cells.

\section{Germinative cells proliferate and are enriched in primary cell preparations}

In the previously described primary cell regeneration system [36], primary cells obtained from E. multilocularis metacestodes initially form small aggregates that grow and fuse to each other. Within these aggregates fluid-filled cavities are formed, and eventually new metacestode vesicles are generated by a still incompletely understood process. We analyzed cell proliferation within the early aggregates (after two days of culture) by EdU labeling. We observed extensive cell proliferation in a layer within the aggregates, but the innermost cells did not incorporate EdU, suggesting that they have exited the cell-cycle, which may be related to the initial formation of internal cavities (typically observed after four days of culture) (Figure 12A). In order to morphologically identify the proliferating cells during regeneration, we prepared cell suspensions by the tissue maceration procedure, and based the identification of cell types on the previously described morphological criteria. As found in metacestodes, germinative cells were the only cell type labeled by EdU in primary cell preparations (Figure $12 \mathrm{C}$ and D). Furthermore, germinative cells were enriched in two day-old aggregates, comprising 62\% to $83 \%$ of all cells, as compared to $32 \%$ to $55 \%$ in the metacestodes that were used to generate the primary cell preparations (three independent primary cell preparations, $P<0.02$ for all preparations, Chi-square test; furthermore, note that the percentage of germinative cells is likely overestimated for the metacestodes since large vesicles were used). Among the differentiated cells, tegumental and glycogen/lipid storage cells were conspicuously few, and an increase in cells with degenerating morphology was noted. Further confirmation of the substantial depletion of tegumental cells was obtained by analyzing the expression of the tegumental cell markers em-muc-1, em-alp-2 and of em-alp-1. Preliminary high throughput RNA sequencing data indicated low expression levels for all three genes in primary cells $(2 \%, 7 \%$ and $0 \%$ of the levels found in the germinal layer, respectively), that was confirmed by semi-quantitative RT-PCR for em-alp-1 and em-alp-2 (Figure 12B).

To confirm the enrichment of germinative cells and to determine which other cell types are present in early primary cell aggregates, we performed transmission electron microscopical studies of two day-old primary cell aggregates. Abundant germinative cells could be found in the aggregates, surrounded by an external layer of cells showing signs of degeneration (necrosis) (Figure 12E and Additional file 17). Also, many muscle fibers and some muscle cells could be identified (Figure 12F). In cryosections of primary cells after three days of culture, muscle fibers were also found by phalloidin staining, and nerve cells were identified by AcTub immunohistofluorescence (Additional file 18). In summary, early primary cell preparations are enriched in proliferating germinative cells, but other cell types such as muscle cells and nerve cells are also present.

\section{Discussion}

\section{Germinative cells are the only proliferating cells in Echinococcus multilocularis larvae}

The germinative cells in E. multilocularis constitute a morphologically homogeneous population, similar to descriptions in other cestode species and life stages [21-24,27], and generally similar to the neoblasts in free living flatworms and the neoblast-like cells of the trematode Schistosoma mansoni [5,62]. The main differences observed within the germinative cells in E. multilocularis were related to the number of nucleoli, size, and the presence or absence of thin cytoplasmic projections. All of these differences could be related in part to normal changes during the cell cycle and cell migration [83,84], although other authors have sub-divided the germinative cells into different types based on size and histological details [21,27]. Germinative cells were identified as the only proliferating cell type during metacestode growth and regeneration, indicating that all new cells must originate from this population. However, the existence of de-differentiation and trans-differentiation processes in 

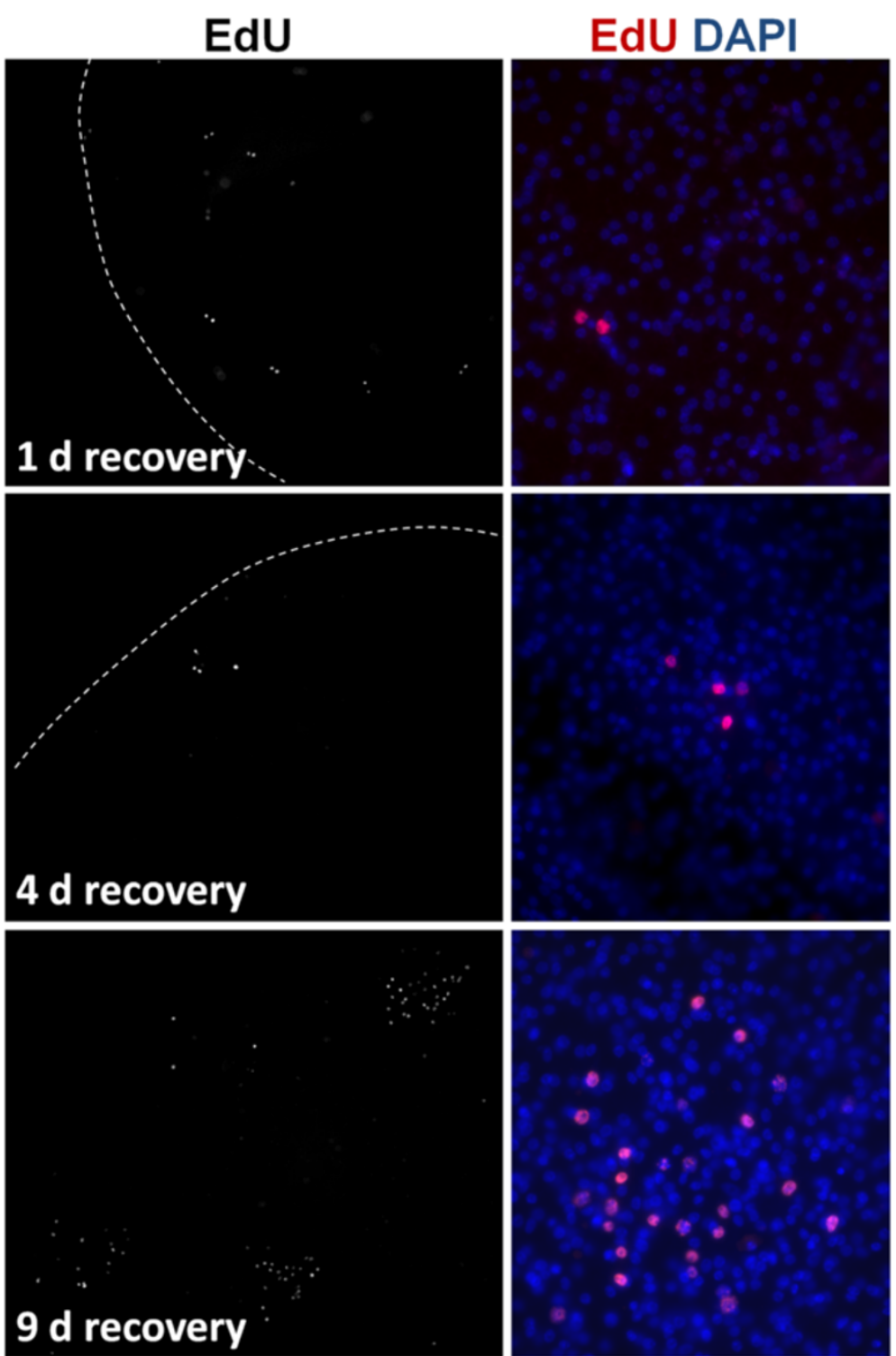

Figure 11 Growing patches of EdU + cells during recovery from hydroxyurea (HU) treatment. Vesicles were treated for seven days with $40 \mathrm{mM} \mathrm{HU}$, transferred to HU-free medium and samples were taken for EdU labeling (five hours with $50 \mu \mathrm{M} \mathrm{EdU}$ ) and detection at the indicated times of recovery.

differentiated cells cannot completely be ruled out at this point. Unambiguous lineage tracing will require analyses mediated by stable genetic markers, and current efforts in our laboratory are being made towards transgenic modification of Echinococcus germinative cells. Furthermore, the markers for differentiated cell types developed in this work will be an important tool for tracing the differentiation pathways of germinative cells.

Unfortunately, so far we have been unable to find a universal molecular marker for the germinative cells. However, H3S10-P and $e m-h 2 B$ are useful endogenous markers to identify the proliferating germinative cells in metacestode tissues, and open the possibility to identify such cells in in vivo material (in the absence of labeling with thymidine analogs). Despite the morphological uniformity of germinative cells, gene expression analyses have clearly shown that the germinative cells are heterogeneous at the molecular level: em-ago-2, em-nos-1 and em-nos-2 genes are only expressed in subpopulations of the proliferating germinative cells. Because Argonaute and Nanos proteins are well known post-transcriptional regulators with important roles in stem cell and germ cell biology $[11,19,85]$, this points to the existence of different sub-populations of germinative cells, perhaps with different self-renewal or differentiation potencies. 

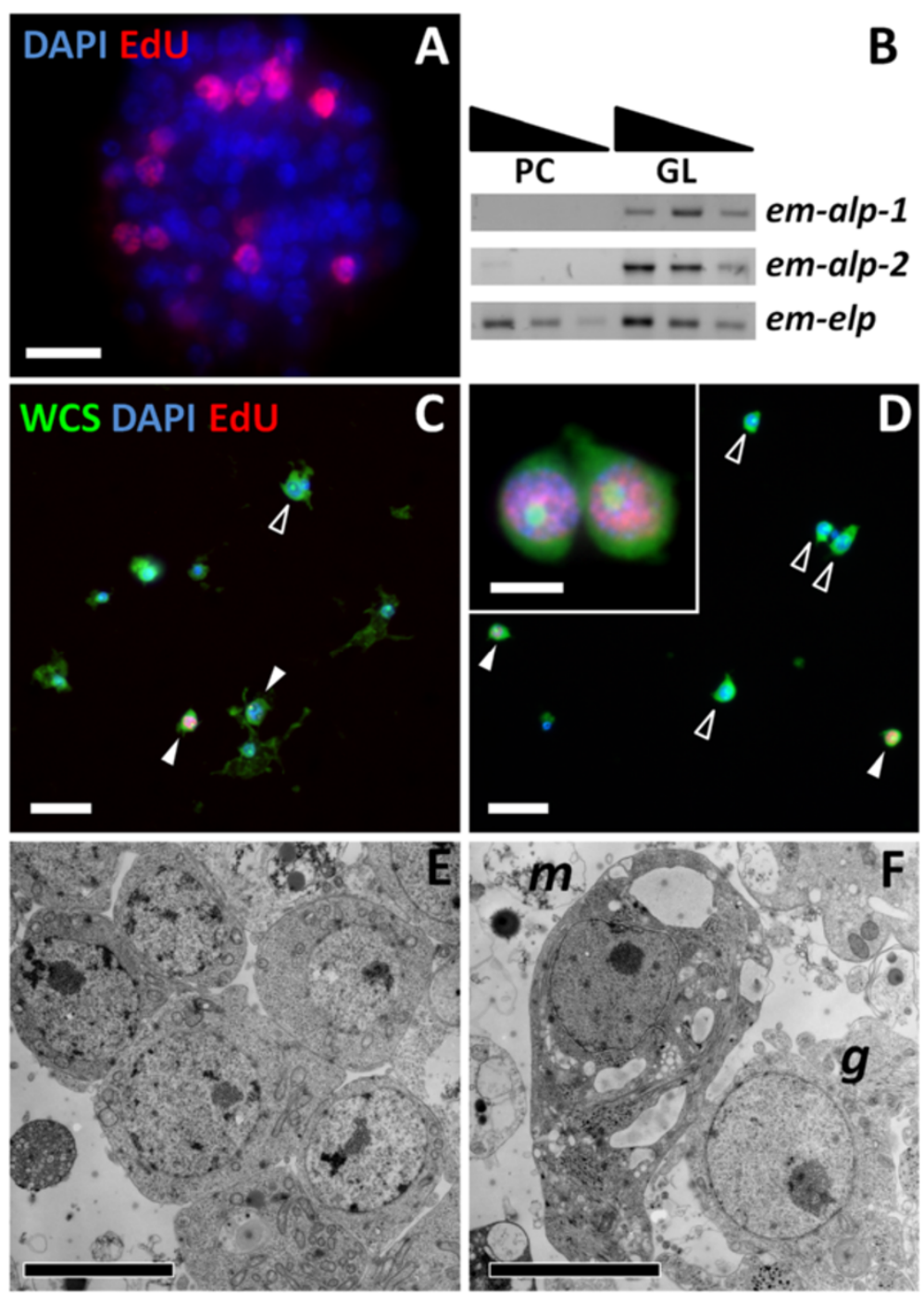

Figure 12 Characterization of early primary cell preparations. (A) EdU incorporation after a $50 \mu \mathrm{m}$ five hour pulse of primary cell aggregates (two days-old). (B) Semi-quantitative RT-PCR of em-alp-1 and em-alp-2 genes with serial ten-fold dilutions of cDNA from primary cells (PC) and germinal layer (GL). The experiment was repeated three times with similar results. (C and $\mathbf{D})$ Representative microscopy fields of cell suspensions obtained from the germinal layer (C) and from primary cells (D). EdU + and EdU - germinative cells are indicated by filled and open arrowheads, respectively. The inset in $\mathrm{D}$ shows a close-up of two $\mathrm{EdU}+$ germinative cells in the primary cell preparations. (E and $\mathbf{F}$ ) Transmission electron microscopy (TEM) of primary cell aggregates (two days-old). (E) Accumulation of germinative cells. (F) A muscle cell (m), containing myofibers and extensive smooth endoplasmic reticulum, and a germinative cell $(\mathrm{g})$ in the periphery of an aggregate. Notice also cell debris surrounding the cells. Bars represent $4 \mu \mathrm{m}$ ( $A, E, F$ and inset in D) and $20 \mu \mathrm{m}$ (C and D).

The capacity for self-renewal of at least some of the germinative cells is strongly suggested by the HUmediated depletion experiments, and is expected given the ability of metacestode tissue to be indefinitely passaged in vivo [34,35]. It is interesting that no proliferation response was observed after milder depletions, and the metacestode vesicles were able to survive for long periods under these conditions. This suggests that the control of cell proliferation is relatively lax in E. multilocularis metacestodes. It is possible that a relatively low number of proliferating germinative cells are enough for basal tissue turnover, but that a larger number is required for actively growing vesicles. Similarly, large differences in the number of EdU incorporating cells can be observed in vesicles incubated ex vivo from a single infected rodent (Koziol and Brehm, unpublished data).

\section{Could cells expressing nanos in Echinococcus} metacestodes represent the germ line?

In many free living flatworms, it is traditionally thought that the germ line is segregated by epigenesis in the juveniles or adults [12]. In fact, the limit between the 
somatic stem cells and the germ line is fluid in planarians and Macrostomum, since the somatic neoblasts are able to contribute to the germ line during regeneration $[74,86,87]$. However, recent studies using molecular markers have allowed the identification of germ cells already at the time of hatching, suggesting that in these flatworms the germ line may be segregated earlier than was previously thought $[74,86]$. For example nanos, another classical germ line marker, has been shown to be expressed only in the planarian germ line stem cells, but not in the morphologically indistinguishable somatic neoblasts [86-88].

In cestodes, it is assumed that the germ line originates by epigenesis, from the germinative cells in the neck region of the developing adult $[12,21,89]$. It is conceivable, however, that a sub-population of the germinative cells could be segregated into the germ line earlier in development, particularly since lineage tracing has never been achieved in cestode embryos [29]. In the case of E. multilocularis, the extensive asexual reproduction and growth in the intermediate host makes an epigenetic mechanism very likely, since early segregation of the germ line by preformation would require incorporation of cells from a segregated germ line within every new vesicle and protoscolex that is asexually generated. Our data suggests that the germinative cell sub-population expressing nanos homologs are not germ line cells: no expression was observed of em-nos-1 during brood capsule and protoscolex development, and em-nos-2 was not consistently observed in brood capsule buds. Moreover, em-nos-2 expression in late protoscolex development suggests a role in the formation of the nervous system. Relatedly, specific nanos paralogs are expressed in the nervous system in many metazoans [90-93].

\section{Echinococcus primary cells as an experimental model for stem cell research}

A great advantage of the E. multilocularis model is the possibility of long term in vitro culture for primary cell preparations, resulting in complete vesicle regeneration [36]. Here, we show that primary cell cultures are enriched for germinative cells, which actively proliferate from the earliest stages of development. Genes enriched in transcriptomic studies of early primary cells and depleted in HU-treated metacestodes could therefore be mined to search for germinative cell-specific expression.

The mechanism for enrichment is not clear, and could involve differential extraction of the germinative cells from the metacestode tissues, differential survival and aggregation of the germinative cells during culture, and the accumulation of germinative cells from selfrenewing divisions. There is indirect evidence supporting all of these mechanisms, since: 1) it has been shown previously that $30 \%$ of all cells in fresh primary cell preparations are in $\mathrm{S}$ and $\mathrm{G} 2 / \mathrm{M}$, making the total percentage of proliferating cells very large before they are set into culture [36], 2) there is evidence of abundant cell death in electron microscopical studies and cell suspensions, and 3) germinative cells actively proliferate in the early aggregates. Besides the germinative cells, differentiated cells such as nerve cells and muscle cells are present in the aggregates. Their role in regeneration, if any, is unknown, but the neuromuscular system has been suggested to influence cell proliferation, differentiation and pattern formation in free living flatworms [94-96].

\section{Differences between the Echinococcus germinative cells and the neoblasts in other flatworms}

The lack of chromatoid bodies and the absence of vasa and piwi orthologs imply important differences between the germinative cells of cestodes and the neoblasts of planarians. Furthermore, genes that are neoblast-specific in planarians, such as hdac1 and phb1, are widely expressed in E. multilocularis. Homologs of these genes have been shown to be important for stem cell biology and cell proliferation in other organisms, but they do not have a stem cell or even a proliferating cell-specific expression in these models [67,97-99]. It is therefore possible that the specific expression of these genes in neoblasts is a planarian novelty, which may not be shared with other flatworms. At the functional level, the response of E. multilocularis to partial germinative cell depletion is also different to that described in free living flatworms, since in planarians and in Macrostomum there is always a quick response by which the neoblast population is restored to normal levels within narrow margins, even when relatively large numbers of neoblasts remain in the tissues [100,101].

Recently, Newmark and colleagues demonstrated the existence of neoblast-like cells in the trematode Schistosoma mansoni, and in this organism, which also lacks vasa and piwi orthologs, paralogs of these genes are specifically expressed in the neoblast-like stem cells and have important roles in their maintenance [62,102]. In Schistosoma mansoni sporocysts the ago2-1 gene (an ortholog of the em-ago2 genes) is expressed in all neoblast-like cells, and nanos-2 is expressed in a large sub-population of neoblast-like cells. In adults, both genes are expressed in many, if not all, somatic stem cells. Therefore, differences can also be observed in the gene expression repertoire between $E$. multilocularis germinative cells and the Schistosoma neoblast-like cells, making the E. multilocularis stem cell system unique among flatworms. Further gene expression studies will depict a clearer picture of their similarities and differences, including the analysis of vasa-like genes (paralogs of vasa such as $P L-10$ ) which are expressed in planarian and schistosome stem cells $[13,18,102]$. 
The E. multilocularis metacestode, with its ability to grow infiltratively like a tumor into the tissues of the host, is a relatively recent evolutionary novelty and is derived from the more typical cysterci larvae found in other taeniid cestodes $[103,104]$. Although rare in most cestodes, asexual reproduction by the formation of new scoleces is found in many taeniids $[103,105-107]$ and it is possible that the huge proliferative potential of $E$. multilocularis germinative cells and larvae was adapted from an already increased potential found in a common taeniid ancestor. The germinative cells in E. multilocularis, although similar in morphology and functionally analogous to the neoblasts in other flatworms, show important differences at the level of gene expression, which could be related to this recent evolutionary change in their developmental biology. At this point, nothing is known about gene expression in the germinative cells of adult cestodes. Because of the biological hazard related to working with E. multilocularis adults, comparative studies in related cestode models such as Hymenolepis microstoma [108] and Mesocestoides corti [24,109] would be of great importance to delineate which characteristics of the germinative cells of $E$. multilocularis metacestodes are unique to this species and larval form, and which are a general feature of cestode germinative cells.

\section{Conclusions}

E. multilocularis is an important model for the study of parasite development and host-parasite interactions, and is the only flatworm model with a robust cell culture system [110]. Growth and regeneration of E. multilocularis larvae is driven by the germinative cells, which are morphologically and functionally similar to the neoblasts of free living flatworms, but which show important differences in their gene expression patterns and in the loss of conserved stem cell regulators. This work represent the first description of the germinative cells at the molecular level, giving the first evidence of the existence of subpopulations of germinative cells with different gene expression patterns, and provides molecular markers for identifying differentiated cell types in situ. Some differences between the germinative cells and the neoblasts of other flatworms could have arisen as specific adaptations of the stem cell system for the unique asexual development of E. multilocularis. The novel development of $E$. multilocularis and other taeniids is therefore an excellent model for the study of the evolutionary origins of asexual reproduction and its effect on stem cell systems.

\section{Additional files}

Additional file 1: List of GeneDB gene codes, primers and probes from this work.
Additional file 2: Representative examples of WMISH experiments and the respective controls performed with sense probes, for genes with different levels of expression.

Additional file 3: Example of a rare mitotic EdU + cell after a $50 \mu \mathrm{M}$ five hour pulse. DAPI staining is shown in blue, EdU detection in red, and tubulin immunohistofluorescence in green. The bar represents $5 \mu \mathrm{m}$.

Additional file 4: EdU incorporation in ex vivo cultured metacestode material. Abbreviations: bc, brood capsule; dev ps, developing protoscoleces; gl, germinal layer; inv ps, invaginated protoscolex; host, host tissue. Bars represent $200 \mu \mathrm{m}$.

Additional file 5: EdU incorporation after protoscolex isolation and activation. The protocol and representative images of EdU incorporation are shown for each condition. The experiment was repeated twice with similar results.

Additional file 6: Histogram of cell areas as seen in cell suspensions (used as a proxy for cell size) for all germinative cells and for EdU + germinative cells in the germinal layer and in primary cell preparations. Smaller cells are less likely to incorporate EdU, and EdU + cells are overrepresented at intermediate sizes. This is compatible with smaller cells being in G1/G0-phase, cells of intermediate size in S-phase and the larger cells in G2-phase. However, it is possible that other factors (such as different germinative cell sub-populations) also affect germinative cell size.

Additional file 7: Example of a EdU + germinative cell in a cell suspension prepared from protoscoleces (previously incubated for five hours in $\mathbf{5 0} \mu \mathrm{M}$ EdU). WCS is shown in green, EdU in red and DAPI in blue.

Additional file 8: Genomic organization of em-ago2 genes. (A) Graphical representation of the end of scaffold 7767 and the beginning of scaffold 7771, showing the position of primers used for PCR with genomic DNA. Both DNA strands and all six reading frames are shown, together with the position of genes and their exons and the em-ago2- $\psi$ pseudogene. (B) PCR with genomic DNA to confirm the structure of both scaffolds. Lanes 1, 2 and 3 in each gel indicate primer sets 1 F/R, 2 F/R, 3 F/R for scaffolds 7767 and 7771, and lane 4 indicates primer set 4 F/R for scaffold 7771. Bands of the expected size are observed in all cases (indicated by red dots) except for the primer combination 7767-3 F/R. It is possible that a difference occurs in the analyzed isolate (MP1) as compared to the reference genome in this particular region.

Additional file 9: Fluorescent WMISH of em-hdac1 on metacestode vesicles. Bars represent $40 \mu \mathrm{m}$.

Additional file 10: WMISH of em-phb1 on metacestode vesicles, on the germinal layer (upper panel), brood capsules (middle panel) and protoscolex buds (lower panel).

Additional file 11: Immunohistofluorescence of PHB1 in sections of Dugesia tahitiensis. (A) General view of a cross section at the level of the pharynx (DAPI stained). (A1 and A2) Detail of the region of the pharynx ( $f$ ) and the nerve cords (Figure A1) and of the mesenchyme surrounding the intestine (i) (Figure A2), as seen with DAPI and PHB1 immunoreactivity. Because of strong auto-fluorescence seen in the region of the gut and epidermis in all fluorescence channels, we also provide the signal in the rhodamine channel for comparison (auto-fluorescence thus appears yellow in the merged image). $\mathrm{PHB1}$ is most strongly expressed in small neoblast-like cells in the mesenchyme and around the nerve cords. (B) Negative control (no primary antibody). Bars represent $50 \mu \mathrm{m}$ in A1, A2 and B, and $20 \mu \mathrm{m}$ in the detailed views.

Additional file 12: Em-PHB1 immunodetection in E. multilocularis. Top, immunohistochemistry (IHC) of PHB1 in sections of a vesicle with brood capsules and protoscoleces. Bottom, control $\mathrm{HC}$ without any primary antibody. Bars represent $20 \mu \mathrm{m}$.

Additional file 13: Details of alkaline phosphatase activity in $E$. multilocularis. (A) Lack of alkaline phosphatase activity in the tegument of the brood capsule. (B) Qualitative assessment of whole-mount alkaline phosphatase activity in the excretory system of activated and non-activated protoscoleces. One hundred and fifty protoscoleces were examined and their signal classified as either strong (strong signal in 
scolex and body), moderate (moderate signal only in scolex or body), weak (barely detectable signal) or not stained (no signal observed).

Additional file 14: Differentiation of nerve cells in EdU continuous labeling experiments. (A) Double detection of AcTub immunohistofluorescence and EdU incorporation after a five hour $50 \mu \mathrm{M}$ pulse. No double positive cells can be detected. (B) Example of a double positive cell after 14 days of incubation in $10 \mu \mathrm{M}$ EdU. (C) Percentage of AcTub + EdU + double positive cells over all AcTub + cells after five hours, seven days and fourteen days of incubation in medium containing $1 \mu \mathrm{M}$ or $10 \mu \mathrm{M}$ EdU (average and standard deviation of two to three metacestode vesicles per time point and condition). Bars represent $20 \mu \mathrm{m}$.

Additional file 15: Immunohistofluorescence with anti-HMWtropomyosin in metacestode sections. (A) Germinal layer. (B) Brood capsule. (C) Brood capsule with a protoscolex bud. (D) Invaginated protoscolex. Arrowheads point to the subtegumental muscle layer, which is greatly thickened in brood capsules as compared to the germinal layer. Bars represent $20 \mu \mathrm{m}$.

Additional file 16: Effect of hydroxyurea (HU) on primary cells. (A) Effect on proliferation as assayed by BrdU incorporation and ELISA detection. The BrdU incorporation levels in non-treated controls was set as $100 \%$ and relative values are shown for $10 \mathrm{mM}$ and $40 \mathrm{mM} \mathrm{HU}$, as well as for the control without BrdU (average and standard deviation of four independent experiments). (B) Effect on new vesicle of regeneration from primary cells after three weeks of culture (average and standard deviation of two independent experiments).

Additional file 17: Example of degenerating cell in TEM analysis of early (two days of culture) primary cell preparations.

Additional file 18: AcTub immunohistofluorescence and phalloidin staining of primary cell aggregates after three days of culture. Bars represent $20 \mu \mathrm{m}$.

\section{Abbreviations}

AcTub: acetylated tubulin alpha; bc: brood capsule; BrdU: 5-bromo-2'deoxyuridine; CHAPS: 3-[(3-cholamidopropyl)dimethylammonio]-1propanesulfonate; CDS: coding domain sequence; DAPI: 4', 6-diamidino-2phenylindole; DEPC: diethyl pyrocarbonate; dNTPs: deoxyribonucleotide triphosphates; EDTA: ethylenediaminetetraacetic acid; EdU: 5-ethynyl-2'deoxyuridine; ELISA: Enzyme-Linked Immunosorbent Assay; FITC: fluorescein isothiocyanate; GL: germinal layer; H3S10-P: histone H3 phosphorylated in Serine 10; HF: hydatid fluid; HMW: high molecular weight; HU: hydroxyurea; LL: laminated layer; MAB: maleic acid buffer; NBT/BCIP: nitro blue tetrazolium chloride and 5-bromo-4-chloro-3-indolyl phosphate; NR: Nile red;

PBS: phosphate buffer saline; PCR: polymerase chain reaction; PFA: paraformaldehyde; PI: propidium iodide; PS: protoscolex: RNP: ribonucleoprotein; RRM: ribonucleotide reductase; RT-PCR: reverse transcription polymerase chain reaction; SSC: saline-sodium citrate buffer; TEA: triethanolamine; TEM: transmission electron microscopy; WCS: Whole Cell Stain; WMISH: whole-mount in situ hybridization.

\section{Competing interests}

The authors declare that they have no competing interests.

\section{Authors' contributions}

UK: contributed to study design, carried out or participated in all experiments, analyzed and interpreted the data, manuscript writing and final approval of the manuscript. KB: designed the study, analyzed and interpreted the data, carried out critical revision and final approval of the manuscript. GK: data collection and interpretation and final approval of the manuscript. TR: data collection and analysis and final approval of the manuscript. LZ: data collection and analysis and final approval of the manuscript. All authors read and approved the final manuscript.

\section{Acknowledgements}

This work was supported by grants from the Deutsche

Forschungsgemeinschaft (DFG; BR 2045/4-1) and the Wellhöfer Foundation (all to KB). UK was supported by a grant of the German Excellence Initiative to the Graduate School of Life Sciences, University of Würzburg. The authors wish to thank Monika Bergmann and Dirk Radloff for excellent technical assistance, Dr. Thomas Kerkau of the Institut für Virologie und
Immunobiologie, Würzburg, for his assistance with the X-ray irradiation equipment, and Hilde Merkert, of the Institute for Molecular Infection Biology, Würzburg, for her assistance with confocal microscopy. This publication was funded by the German Research Foundation (DFG) and the University of Würzburg in the funding program Open Access Publishing.

\section{Author details}

${ }^{1}$ Institute of Hygiene and Microbiology, University of Würzburg, Josef-Schneider-Strasse 2, D-97080 Würzburg, Germany. ${ }^{2}$ Department of Electron Microscopy, University of Würzburg, Biocenter, D-97078 Würzburg, Germany. ${ }^{3}$ Facultad de Ciencias, Sección Bioquímica y Biología Molecular, Universidad de la República, Iguá 4225, CP 11400 Montevideo, Uruguay.

Received: 5 November 2013 Accepted: 30 January 2014

Published: 6 March 2014

\section{References}

1. Hyman LH: The Invertebrates: Platyhelminthes and Rhynchocoela, The Acoelomate Bilateria. Volume llth edition. McGraw-Hill; 1951.

2. Egger B, Gschwentner R, Rieger R: Free-living flatworms under the knife: past and present. Dev Genes Evol 2007, 217:89-104.

3. Martin-Duran JM, Egger B: Developmental diversity in free-living flatworms. Evodevo 2013, 3:7.

4. Ax P: Multicellular Animals - A New Approach to the Phylogenetic Order in Nature - Vol I. Berlin: Springer Verlag; 1996.

5. Reuter M, Kreshchenko N: Flatworm asexual multiplication implicates stem cells and regeneration. Can J Zool 2004, 82:334-356.

6. Koziol U, Castillo E: Cell proliferation and differentiation in cestodes. In Research in Helminths. Edited by Esteves A. Kervala, India: Transworld Research Network; 2011:121-138.

7. Wagner DE, Wang IE, Reddien PW: Clonogenic neoblasts are pluripotent adult stem cells that underlie planarian regeneration. Science 2011, 332:811-816.

8. Baguñà J, Saló E, Auladell C: Regeneration and pattern formation in planarians III. Evidence that neoblasts are totipotent stem cells and the source of blastema cells. Development 1989, 108:77-86.

9. Rink JC: Stem cell systems and regeneration in planaria. Dev Genes Evol 2013, 223:67-84

10. Rossi L, Salvetti A, Batistoni R, Deri P, Gremigni V: Planarians, a tale of stem cells. Cell Mol Life Sci 2008, 65:16-23.

11. Ewen-Campen B, Schwager EE, Extavour CG: The molecular machinery of germ line specification. Mol Reprod Dev 2010, 77:3-18.

12. Extavour CG, Akam M: Mechanisms of germ cell specification across the metazoans: epigenesis and preformation. Development 2003, 130:5869-5884.

13. Wagner DE, Ho JJ, Reddien PW: Genetic regulators of a pluripotent adult stem cell system in planarians identified by RNAi and clonal analysis. Cell Stem Cell 2012, 10:299-311.

14. Onal P, Grun D, Adamidi C, Rybak A, Solana J, Mastrobuoni G, Wang Y, Rahn HP, Chen W, Kempa S, et al: Gene expression of pluripotency determinants is conserved between mammalian and planarian stem cells. Embo J 2012, 31:2755-2769.

15. Eisenhoffer GT, Kang H, Sanchez Alvarado A: Molecular analysis of stem cells and their descendants during cell turnover and regeneration in the planarian Schmidtea mediterranea. Cell Stem Cell 2008, 3:327-339.

16. Rossi L, Salvetti A, Marincola FM, Lena A, Deri P, Mannini L, Batistoni R, Wang E, Gremigni V: Deciphering the molecular machinery of stem cells: a look at the neoblast gene expression profile. Genome Biol 2007, 8:R62.

17. Labbe RM, Irimia M, Currie KW, Lin A, Zhu SJ, Brown DD, Ross EJ, Voisin V, Bader GD, Blencowe BJ, Pearson BJ: A comparative transcriptomic analysis reveals conserved features of stem cell pluripotency in planarians and mammals. Stem Cells 2012, 30:1734-1745.

18. Rouhana L, Shibata N, Nishimura O, Agata K: Different requirements for conserved post-transcriptional regulators in planarian regeneration and stem cell maintenance. Dev Biol 2010, 341:429-443.

19. Juliano CE, Swartz SZ, Wessel GM: A conserved germline multipotency program. Development 2010, 137:4113-4126.

20. Baguñà J, Riutort M: Molecular phylogeny of the Platyhelminthes. Can J Zool 2004, 82:168-193.

21. Sulgostowska T: The development of organ systems in cestodes. I. A study of histology of H. diminuta (Rudolphi, 1819). Acta Parasit Pol 1972, 20:449-462 
22. Bolla RI, Roberts LS: Developmental physiology of cestodes. IX. Cytological characteristics of the germinative region of Hymenolepis diminuta. J Parasitol 1971, 57:267-277.

23. Gustafsson MK: Studies on cytodifferentiation in the neck region of Diphyllobothrium dendriticum Nitzsch, 1824 (Cestoda, Pseudophyllidea). Z Parasitenkd 1976, 50:323-329.

24. Koziol U, Dominguez MF, Marin M, Kun A, Castillo E: Stem cell proliferation during in vitro development of the model cestode Mesocestoides cort from larva to adult worm. Front Zool 2010, 7:22

25. Mead RW: Changes in germinative cell frequencies in the germinative region of Hymenolepis diminuta during development. J Parasitol 1982, 68:95-99.

26. Wikgren B-J, Gustafsson MKS: Cell proliferation and histogenesis in diphyllobothrid tapeworms (Cestoda). Acta Acad Abo Ser B 1971, 31:1-10.

27. Douglas LT: The development of organ systems in nematotaeniid cestodes. I. Early histogenesis and formation of reproductive structures in Baerietta diana (Helfer, 1948). J Parasitol 1961, 47:669-680.

28. Sakamoto T, Sugimura M: Studies on echinococcosis XXIII. Electron microscopical observations on histogenesis of larval Echinococcus multilocularis. Jap J vet Res 1970, 18:131-144.

29. Rybicka K: Embryogenesis in cestodes. Adv Parasitol 1966, 4:107-186.

30. Henderson DJ, Hanna RE: Hymenolepis nana (Cestoda: Cyclophyllidea): DNA, RNA and protein synthesis in 5-day-old juveniles. Int J Parasitol 1988, 18:963-972.

31. Eckert J, Thompson RC, Mehlhorn H: Proliferation and metastases formation of larval Echinococcus multilocularis. I. Animal model, macroscopical and histological findings. Z Parasitenkd 1983, 69:737-748.

32. Mehlhorn H, Eckert J, Thompson RC: Proliferation and metastases formation of larval Echinococcus multilocularis II. Ultrastructural investigations. Z Parasitenkd 1983, 69:749-763.

33. Eckert J, Deplazes P: Biological, epidemiological, and clinical aspects of echinococcosis, a zoonosis of increasing concern. Clin Microbiol Rev 2004 17:107-135.

34. Spiliotis M, Brehm K: Axenic in vitro cultivation of Echinococcus multilocularis metacestode vesicles and the generation of primary cell cultures. Methods Mol Biol 2009, 470:245-262.

35. Norman L, Kagan IG: The maintenance of Echinococcus multilocularis in gerbils (Meriones unguiculatus) by intraperitoneal inoculation. J Parasitol 1961, 47:870-874.

36. Spiliotis M, Lechner S, Tappe D, Scheller C, Krohne G, Brehm K: Transient transfection of Echinococcus multilocularis primary cells and complete in vitro regeneration of metacestode vesicles. Int J Parasitol 2008, 38:1025-1039.

37. Galindo M, Paredes R, Marchant C, Mino V, Galanti N: Regionalization of DNA and protein synthesis in developing stages of the parasitic platyhelminth Echinococcus granulosus. J Cell Biochem 2003, 90:294-303.

38. Tsai IJ, Zarowiecki M, Holroyd N, Garciarrubio A, Sanchez-Flores A, Brooks KL, Tracey A, Bobes RJ, Fragoso G, Sciutto E, et al: The genomes of four tapeworm species reveal adaptations to parasitism. Nature 2013, 496:57-63.

39. Lascano EF, Coltorti EA, Varela-Diaz VM: Fine structure of the germinal membrane of Echinococcus granulosus cysts. J Parasitol 1975, 61:853-860.

40. Koziol U, Krohne G, Brehm K: Anatomy and development of the larval nervous system in Echinococcus multilocularis. Front Zool 2013, 10:24.

41. Jura H, Bader A, Hartmann M, Maschek H, Frosch M: Hepatic tissue culture model for study of host-parasite interactions in alveolar echinococcosis. Infect Immun 1996, 64:3484-3490.

42. Tappe D, Brehm K, Frosch M, Blankenburg A, Schrod A, Kaup FJ, MatzRensing K: Echinococcus multilocularis infection of several Old World monkey species in a breeding enclosure. Am J Trop Med Hyg 2007, 77:504-506.

43. Peter $R$, Ladurner $P$, Rieger RM: The role of stem cell strategies in coping with environmental stress and choosing between alternative reproductive modes: Turbellaria rely on a single cell type to maintain individual life and propagate species. Mar Ecol 2001, 22:35-51.

44. David CN: A quantitative method for maceration of Hydra tissue. Wilhelm Roux' Archiv 1973, 171:259-268.

45. Greenspan P, Mayer EP, Fowler SD: Nile red: a selective fluorescent stain for intracellular lipid droplets. J Cell Biol 1985, 100:965-973.

46. Heeney MM, Whorton MR, Howard TA, Johnson CA, Ware RE: Chemical and functional analysis of hydroxyurea oral solutions. J Pediatr Hematol Oncol 2004, 26:179-184.
47. Brehm K, Wolf M, Beland H, Kroner A, Frosch M: Analysis of differential gene expression in Echinococcus multilocularis larval stages by means of spliced leader differential display. Int J Parasitol 2003, 33:1145-1159.

48. Cox WG, Singer VL: A high-resolution, fluorescence-based method for localization of endogenous alkaline phosphatase activity. J Histochem Cytochem 1999, 47:1443-1456.

49. Koziol U, Costabile A, Dominguez MF, Iriarte A, Alvite G, Kun A, Castillo E: Developmental expression of high molecular weight tropomyosin isoforms in Mesocestoides corti. Mol Biochem Parasitol 2011, 175:181-191.

50. Alvite G, Esteves A: Echinococcus granulosus tropomyosin isoforms: from gene structure to expression analysis. Gene 2009, 433:40-49.

51. Sambrook J, Fritsch EF, Maniatis T: Molecular Cloning. New York: Cold Spring Harbor Laboratory Press; 1989.

52. Hopman AH, Ramaekers FC, Speel EJ: Rapid synthesis of biotin-, digoxigenin-, trinitrophenyl-, and fluorochrome-labeled tyramides and their application for in situ hybridization using CARD amplification. J Histochem Cytochem 1998, 46:771-777.

53. Salic A, Mitchison TJ: A chemical method for fast and sensitive detection of DNA synthesis in vivo. Proc Natl Acad Sci USA 2008, 105:2415-2420.

54. Hendzel MJ, Wei Y, Mancini MA, Van Hooser A, Ranalli T, Brinkley BR, BazettJones DP, Allis CD: Mitosis-specific phosphorylation of histone $\mathrm{H} 3$ initiates primarily within pericentromeric heterochromatin during $\mathrm{G} 2$ and spreads in an ordered fashion coincident with mitotic chromosome condensation. Chromosoma 1997, 106:348-360.

55. Wikgren BJ, Gustafsson MK: Duration of the cell cycle of germinative cells in plerocercoids of Diphyllobothrium dendriticum. Z Parasitenkd 1967, 29:275-281.

56. Gustafsson MKS: Basic cell types in Echinococcus granulosus (Cestoda, Cyclophyllidea). Acta Zool Fenn 1976, 146:1-16.

57. Baguñà J, Romero R: Quantitative analysis of cell types during growth, degrowth and regeneration in the planarians Dugesia $(S)$ mediterranea and Dugesia (G) tigrina. Hydrobiologia 1981, 84:181-194.

58. Loehr KA, Mead RW: A maceration technique for the study of cytological development in Hymenolepis citelli. J Parasitol 1979, 65:886-889.

59. Newmark PA, Sanchez Alvarado A: Bromodeoxyuridine specifically labels the regenerative stem cells of planarians. Dev Biol 2000, 220:142-153.

60. Jaeger S, Barends S, Giege R, Eriani G, Martin F: Expression of metazoan replication-dependent histone genes. Biochimie 2005, 87:827-834.

61. Solana J, Kao D, Mihaylova Y, Jaber-Hijazi F, Malla S, Wilson R, Aboobaker A Defining the molecular profile of planarian pluripotent stem cells using a combinatorial RNAseq. RNA interference and irradiation approach. Genome Biol 2012, 13:R19.

62. Collins JJ 3rd, Wang B, Lambrus BG, Tharp ME, Iyer H, Newmark PA: Adult somatic stem cells in the human parasite Schistosoma mansoni. Nature 2013, 494:476-479.

63. Mochizuki K, Sano H, Kobayashi S, Nishimiya-Fujisawa C, Fujisawa T: Expression and evolutionary conservation of nanos-related genes in Hydra. Dev Genes Evol 2000, 210:591-602.

64. Rebscher N, Zelada-Gonzalez F, Banisch TU, Raible F, Arendt D: Vasa unveils a common origin of germ cells and of somatic stem cells from the posterior growth zone in the polychaete Platynereis dumerilii. Dev Biol 2007, 306:599-611.

65. Spiliotis M, Mizukami C, Oku Y, Kiss F, Brehm K, Gottstein B: Echinococcus multilocularis primary cells: improved isolation, small-scale cultivation and RNA interference. Mol Biochem Parasitol 2010, 174(1):83-87.

66. Zhu SJ, Pearson BJ: The retinoblastoma pathway regulates stem cell proliferation in freshwater planarians. Dev Biol 2013, 373:442-452.

67. Merkwirth $C$, Langer T: Prohibitin function within mitochondria: essential roles for cell proliferation and cristae morphogenesis. Biochim Biophys Acta 2009, 1793:27-32

68. Diaz A, Casaravilla C, Irigoin F, Lin G, Previato JO, Ferreira F: Understanding the laminated layer of larval Echinococcus I: structure. Trends Parasitol 2011, 27:204-213.

69. Parkinson J, Wasmuth JD, Salinas G, Bizarro CV, Sanford C, Berriman M, Ferreira HB, Zaha A, Blaxter ML, Maizels RM, Fernandez C: A transcriptomic analysis of Echinococcus granulosus larval stages: implications for parasite biology and host adaptation. PLoS Negl Trop Dis 2012, 6:e1897.

70. Del Cacho E, Causape C, Sanchez-Acedo C, Quilez J: Cytochemical study of the germinal membrane of the Echinococcus granulosus cyst. Vet Parasitol 1996, 62:101-106. 
71. Arsac C, Walbaum S, Sarciron ME, Petavy AF: Histochemical observations of alkaline phosphatase activity of Echinococcus multilocularis during in vivo development in golden hamsters, an alternative definitive host. Exp Anim 1997, 46:25-30.

72. Halton DW, Maule AG: Flatworm nerve-muscle: structural and functional analysis. Can J Zool 2003, 82:316-333.

73. Smyth JD, McManus DP: The Physiology and Biochemistry of Cestodes. Cambridge: Cambridge University Press; 2007.

74. Pfister D, De Mulder K, Hartenstein V, Kuales G, Borgonie G, Marx F, Morris J, Ladurner P: Flatworm stem cells and the germ line: developmental and evolutionary implications of macvasa expression in Macrostomum lignano. Dev Biol 2008, 319:146-159.

75. Pfister D, De Mulder K, Philipp I, Kuales G, Hrouda M, Eichberger P, Borgonie G, Hartenstein V, Ladurner P: The exceptional stem cell system of Macrostomum lignano: screening for gene expression and studying cell proliferation by hydroxyurea treatment and irradiation. Front Zool 2007, 4:9.

76. Pohle S, Ernst R, MacKenzie C, Spicher M, Romig T, Hemphill A, Gripp S: Echinococcus multilocularis: the impact of ionizing radiation on metacestodes. Exp Parasitol 2011, 127:127-134.

77. Farber E, Baserga R: Differential effects of hydroxyurea on survival of proliferating cells in vivo. Cancer Res 1969, 29:136-139.

78. Krakoff $I H$, Brown NC, Reichard P: Inhibition of ribonucleoside diphosphate reductase by hydroxyurea. Cancer Res 1968, 28:1559-1565.

79. Sinclair WK: Hydroxyurea: differential lethal effects on cultured mammalian cells during the cell cycle. Science 1965, 150:1729-1731.

80. De Mulder K, Kuales G, Pfister D, Willems M, Egger B, Salvenmoser W, Thaler M, Gorny AK, Hrouda M, Borgonie G, Ladurner P: Characterization of the stem cell system of the acoel Isodiametra pulchra. BMC Dev Biol 2009, 9:69.

81. Salo E, Baguna J: Regeneration and pattern formation in planarians. I. The pattern of mitosis in anterior and posterior regeneration in Dugesia $(G)$ tigrina, and a new proposal for blastema formation. J Embryol Exp Morphol 1984, 83:63-80.

82. Petermann E, Orta ML, Issaeva N, Schultz N, Helleday T: Hydroxyurea-stalled replication forks become progressively inactivated and require two different RAD51-mediated pathways for restart and repair. Mol Cell 2010, 37:492-502

83. Wachtler F, Stahl A: The nucleolus: a structural and functional interpretation. Micron 1993, 24:473-505.

84. Alberts B: Molecular Biology of the Cell. New York: Garland Science; 2000

85. Carmell MA, Xuan Z, Zhang MQ, Hannon GJ: The Argonaute family: tentacles that reach into RNAi, developmental control, stem cell maintenance, and tumorigenesis. Genes Dev 2002, 16:2733-2742.

86. Handberg-Thorsager M, Salo E: The planarian nanos-like gene Smednos is expressed in germline and eye precursor cells during development and regeneration. Dev Genes Evol 2007, 217:403-411.

87. Sato K, Shibata N, Orii H, Amikura R, Sakurai T, Agata K, Kobayashi S, Watanabe K: Identification and origin of the germline stem cells as revealed by the expression of nanos-related gene in planarians. Dev Growth Differ 2006, 48:615-628.

88. Wang Y, Zayas RM, Guo T: Newmark PA: nanos function is essential for development and regeneration of planarian germ cells. Proc Natl Acad SCi USA 2007, 104:5901-5906.

89. Gustafsson MKS: The cells of a cestode. Diphyllobothrium dendriticum as a model in cell biology. Acta Acad Abo Ser B 1990, 50:13-44.

90. Haraguchi S, Tsuda M, Kitajima S, Sasaoka Y, Nomura-Kitabayashid A, Kurokawa K, Saga Y: nanos1: a mouse nanos gene expressed in the central nervous system is dispensable for normal development. Mech Dev 2003, 120:721-731

91. Aoki Y, Nakamura S, Ishikawa Y, Tanaka M: Expression and syntenic analyses of four nanos genes in medaka. Zoolog Sci 2009, 26:112-118.

92. Ye B, Petritsch C, Clark IE, Gavis ER, Jan LY, Jan YN: Nanos and Pumilio are essential for dendrite morphogenesis in Drosophila peripheral neurons. Curr Biol 2004, 14:314-321.

93. Kanska J, Frank U: New roles for Nanos in neural cell fate determination revealed by studies in a cnidarian. J Cell Sci 2013, 126:3192-3203.

94. Rossi L, lacopetti P, Salvetti A: Stem cells and neural signaling: the case of neoblast recruitment and plasticity in low dose X-ray treated planarians. Int J Dev Biol 2012, 56:135-142.
95. Reuter M, Gustafsson M: Neuronal signal substances in asexual multiplication and development in flatworms. Cell Mol Neurobiol 1996, 16:591-616

96. Witchley JN, Mayer M, Wagner DE, Owen JH, Reddien PW: Muscle cells provide instructions for planarian regeneration. Cell Rep 2013, 4:633-641.

97. Brunmeir R, Lagger S, Seiser C: Histone deacetylase HDAC1/HDAC2controlled embryonic development and cell differentiation. Int J Dev Biol 2009, 53:275-289.

98. MacDonald JL, Roskams AJ: Histone deacetylases 1 and 2 are expressed at distinct stages of neuro-glial development. Dev Dyn 2008, 237:2256-2267.

99. Murko C, Lagger S, Steiner M, Seiser C, Schoefer C, Pusch O: Expression of class I histone deacetylases during chick and mouse development. Int J Dev Biol 2010, 54:1527-1537.

100. Salvetti A, Rossi L, Bonuccelli L, Lena A, Pugliesi C, Rainaldi G, Evangelista M, Gremigni V: Adult stem cell plasticity: neoblast repopulation in non-lethally irradiated planarians. Dev Biol 2009, 328:305-314.

101. De Mulder K, Kuales G, Pfister D, Egger B, Seppi T, Eichberger P, Borgonie G, Ladurner P: Potential of Macrostomum lignano to recover from gammaray irradiation. Cell Tissue Res 2010, 339:527-542.

102. Wang B, Collins JJ 3rd, Newmark PA: Functional genomic characterization of neoblast-like stem cells in larval Schistosoma mansoni. Elife 2013, 2:e00768.

103. Slais J: Functional morphology of cestode larvae. Adv Parasitol 1973, 11:395-480.

104. Freeman RS: Ontogeny of cestodes and its bearing on their phylogeny and systematics. Adv Parasitol 1973, 11:481-557.

105. Loos-Frank B: An up-date of Verster's (1969) 'Taxonomic revision of the genus Taenia Linnaeus' (Cestoda) in table format. Syst Parasitol 2000, 45:155-183.

106. Moore J, Brooks DR: Asexual reproduction in Cestodes (Cyclophyllidea: Taeniidae): Ecological and Phylogenetic Influences. Evolution 1987 41:882-891.

107. Toledo A, Cruz C, Fragoso G, Laclette JP, Merchant MT, Hernandez M, Sciutto E: In vitro culture of Taenia crassiceps larval cells and cyst regeneration after injection into mice. J Parasitol 1997, 83:189-193.

108. Cunningham LJ, Olson PD: Description of Hymenolepis microstoma (Nottingham strain): a classical tapeworm model for research in the genomic era. Parasit Vectors 2010, 3:123

109. Specht D, Voge M: Asexual multiplication of Mesocestoides tetrathyridia in laboratory animals. J Parasitol 1965, 51:268-272

110. Brehm K: Echinococcus multilocularis as an experimental model in stem cell research and molecular host-parasite interaction. Parasitology 2010, 137:537-555.

doi:10.1186/2041-9139-5-10

Cite this article as: Koziol et al:: The unique stem cell system of the immortal larva of the human parasite Echinococcus multilocularis. EvoDevo 2014 5:10.

\section{Submit your next manuscript to BioMed Central and take full advantage of:}

- Convenient online submission

- Thorough peer review

- No space constraints or color figure charges

- Immediate publication on acceptance

- Inclusion in PubMed, CAS, Scopus and Google Scholar

- Research which is freely available for redistribution 